\title{
Enhancement of the summer extreme precipitation over North China by interactions between moisture convergence and topographic settings
}

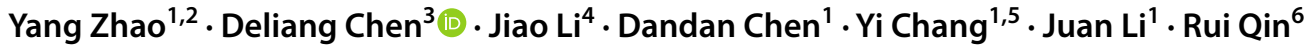

Received: 1 August 2019 / Accepted: 14 January 2020 / Published online: 23 January 2020

(c) The Author(s) 2020

\begin{abstract}
This study investigates the roles of atmospheric moisture transport under the influence of topography for summer extreme precipitation over North China (NC) during 1979-2016. Based on rain gauge precipitation data and a reanalysis, 38 extreme precipitation days in NC during the 38 years were selected and associated moisture fluxes estimated. The results show that there is a dominant moisture influx of $311.8 \mathrm{~kg} \mathrm{~m}^{-1} \mathrm{~s}^{-1}$ into $\mathrm{NC}$ along its southern boundary from tropical oceans, and a secondary influx of $107.9 \mathrm{~kg} \mathrm{~m}^{-1} \mathrm{~s}^{-1}$ across its western boundary carried by mid-latitude westerlies. The outflux across the eastern boundary is $206.9 \mathrm{~kg} \mathrm{~m}^{-1} \mathrm{~s}^{-1}$ and across the northern boundary is $76.0 \mathrm{~kg} \mathrm{~m}^{-1} \mathrm{~s}^{-1}$, giving a net moisture gain over $\mathrm{NC}$ of $136.8 \mathrm{~kg} \mathrm{~m}^{-1} \mathrm{~s}^{-1}$. During extreme precipitation days, the moisture flux convergence (MFC) was much larger, exceeding $4 \times 10^{-5} \mathrm{~kg} \mathrm{~m}^{-1} \mathrm{~s}^{-1}$. The MFC maximum core, the pronounced moisture transport, and the striking extreme precipitation zone over NC are all anchored to the east of the steep slopes of the surrounding topography. Moreover, a remarkably high humidity and strong upward motion also occur near steep slopes, indicating the critical role of the adjacent topography on the extreme precipitations. Simulations with and without the topography in NC using the Weather and Research Forecasting model for six selected out of the 38 extreme precipitation days demonstrate that the surrounding topography reinforces the MFC over NC by $16 \%$ relative to the case without terrain, primarily through enhanced wind convergence and higher moisture content, as well as stronger vertical motion induced by diabatic heating. The interactions between moisture convergence and topographic settings strengthen the extreme precipitation over NC.
\end{abstract}

Keywords North China $\cdot$ Extreme precipitation $\cdot$ Moisture budget $\cdot$ Moisture flux convergence $\cdot$ Topography

\section{Introduction}

Deliang Chen

deliang@gvc.gu.se

$\triangle \mathrm{Jiao} \mathrm{Li}$

lijiao0606@126.com

1 State Key Laboratory of Severe Weather, Chinese Academy of Meteorological Sciences, Beijing, China

2 Department of Atmospheric and Oceanic Sciences, McGill University, Montreal, QC, Canada

3 Regional Climate Group, Department of Earth Sciences, University of Gothenburg, Gothenburg, Sweden

4 Henan Province Climate Center, Zhengzhou, China

5 Key Laboratory for Cloud Physics, China Meteorological Administration, Beijing, China

6 Institute of Urban Meteorology, China Meteorological Administration, Beijing, China
Extreme precipitation events lead to huge economic losses and fatalities globally every year (Mirza 2002; Jonkman 2005; Gemmer et al. 2008). North China (NC; $35^{\circ}-42^{\circ}$ $\left.\mathrm{N}, 110^{\circ}-120^{\circ} \mathrm{E}\right)$ is a key political and economic region of China with high population density and substantial agriculture production. However, the socioeconomic conditions in $\mathrm{NC}$ are especially vulnerable to extreme precipitation, which cost thousands of millions of dollars in damage every year (Gao and Wang 2017). In recent years, extreme precipitation events over NC have occurred frequently. For example, $\mathrm{NC}$ witnessed five extreme precipitation events in August 2010 (Orsolini et al. 2015). On 21-22 July 2012, a disastrous rainstorm hit Beijing with a maximum daily precipitation reaching $460 \mathrm{~mm}$ (Liu and Wang 2013; Zhou et al. 2013). Researching on extreme precipitation over NC is a crucial issue in terms of regional disaster prevention and mitigation, 
and the management of water resources and agricultural irrigation.

One necessary condition for extreme precipitation's occurrence is sufficient moisture supply (Zhou and Yu 2005; Holman and Vavrus 2012). NC is located on the north margin of the East Asian summer monsoon and receives the bulk of its precipitation during the summer season (Guo et al. 2012). Moisture transport plays an essential role in extreme precipitation during summer (Zhang 1999). Jiang et al. (2014) demonstrated that the southeast and southwest monsoon flows into Beijing with abundant moisture continuously enhanced the low-layer moisture flux and convergence during the Beijing "7.21" heavy-rain case. Zhong et al. (2015) also captured that this heavy rainfall event occurred under the low-level warm and moist southeasterly flows.

Numerous studies have been devoted to studying the roles played by moisture supply for summer extreme precipitation over NC. Zhang and Li (2014) estimated the moisture contributions to a rainstorm over Shandong province in the southern $\mathrm{NC}$, indicating that the moisture supply was originated mainly from neighboring southwest China, whereas little moisture came from the nearby western Pacific. Chen et al. (2018) analyzed the relative contributions of moisture from the Arabian Sea, the Bay of Bengal, and the South China Sea to summer precipitation over mainland China, and found that these three oceanic sources make diverse contributions on different time scales.

Previous works have identified the water vapor path contributing to summer extreme precipitation over NC. Liang et al. (2007) reported that moisture from the western Pacific carried by mid-latitude westerlies has a great impact on the occurrence of summer extreme precipitation over NC, while moisture from the Bay of Bengal intensifies torrential rain to some extent. Zhang et al. (2013) pointed out that it is the convective cells along a quasi-stationary linear convective system and a deep layer of southerly moisture supply that were responsible for the heavy rainfall on 21 July 2012. Jiang et al. (2014) also discussed this "7.21" rainstorm event in Beijing and claimed that strong southwest monsoon stream transport water vapor to Beijing continuously, with remarkable water vapor convergence into the rainstorm system. Wang and Liu (2017) documented that the strong moisture transport path from the Bay of Bengal was one key factor related to the rainstorm over Central China. However, these results did not investigate extreme precipitation over $\mathrm{NC}$ and related water vapour transport in a quantitative way. Also, they have not considered the effect of surrounding terrain on extreme precipitation over NC. This study intends to fill this knowledge gap.

Quantitative analysis of moisture transport is useful for identifying relative contributions of diverse moisture sources to extreme precipitation in a region. Moisture flux convergence (MFC) has been considered to directly characterize the behavior of extreme precipitation (Fankhauser 1965; Cook et al. 2008; Chou et al. 2009; Zhou et al. 2017). MFC includes two terms: wind convergence and moisture advection. Some studies have been devoted to quantifying the moisture budget of summer extreme precipitation over NC. Freychet et al. (2015) demonstrated that increased MFC accompanied by northward winds provides a favorable background for torrential rainfall intensification over NC. Wang et al. (2014) simulated the net budget of water vapour of a rainstorm over NC in the summer of 2011, and indicated that the net budget was always positive during this rainstorms process and the contribution of the two terms of MFC was diverse during different state of this rainstorm event. The torrential rainfall over NC during the summer of 2007 was attributable to reinforced MFC as a result of small variations in the vertical advection term (Chen and Tomassiniand 2015). Zhao et al. (2019a) reported that the wind convergence component (accounting for $79.1 \%$ of the MFC) had a critical effect on strengthening MFC at $925 \mathrm{hPa}$ relative to the moisture advection part (accounting for 20.9\% of the MFC) in seven historical summer rainstorm cases over NC. These studies have quantified how the moisture budget and corresponding MFC at a specific level are associated with a summer extreme precipitation over NC.

$\mathrm{NC}$ experiences the second- and third-largest landforms with complex topography in China; i.e., the Loess Plateau with elevations from 500 to $2000 \mathrm{~m}$ situated west of the $\mathrm{NC}$ region, and the eastern flat plain to its east (Wang et al. 2013). The remarkable Taihang and Yanshan Mountains, with altitudes of $800-2000 \mathrm{~m}$, are located along the western and northern margins of $\mathrm{NC}$, respectively (He and Zhang 2010). Sun et al. (2015) inferred that the complex terrain surrounding $\mathrm{NC}$ interferes with circulation patterns, giving rise to conditions that are conducive to extreme summer precipitation over the region. $\mathrm{Li}$ et al. (2017) obtained that higher-(lower) frequency hourly heavy rainfall events, along with more (less) accumulated rainfall amounts, occur over Beijing's northeast mountains (west and northwest mountains), and identified the positive effect of mountain-plain circulation on the generation of the hourly heavy rainfall event in warm season. Wang et al. (2014) indicated that the simulated moisture transport for a summer torrential rain case over NC was mainly influenced by the Taihang Mountain. Liao et al. (2009) used numerical simulations over the Taihang Mountains to demonstrate that the elevated topography favors convection and summer precipitation over NC from a cloud physics perspective. While the existing literature has identified the significant impact of surrounding terrains on summer extreme precipitation over $\mathrm{NC}$, the effect of terrains on modulating moisture budget to further induce summer extreme precipitation over NC deserves to be better understood and quantified. 
Given the above considerations, this study aims to quantify and simulate the whole column moisture budget for summer extreme precipitation events over $\mathrm{NC}$ under the influence of the topography. Such a research could enhance our understanding of the atmospheric hydrological cycle during periods of extreme precipitation over NC, and has the potential to improve the accuracy of regional forecasts of extremes.

\section{Data and methods}

\subsection{Data}

A daily precipitation dataset containing data from more than 2400 rain gauge stations over China during 1979-2016 has been released by the National Meteorological Information Center (NMIC) of the China Meteorological Administration (CMA) (http://nmic.cn/web/index.htm/). This dataset has undergone quality control processes (Zhang et al. 2016; Zhong et al. 2016). We selected 139 fairly evenly distributed surface meteorological stations in the region $35^{\circ}-42.0^{\circ}$ $\mathrm{N}$ and $110^{\circ}-120^{\circ} \mathrm{E}$ defined as $\mathrm{NC}$ (Fig. 1a). A gauge was included if it had less than $15 \%$ missing values.

Gridded horizontal and vertical winds, specific humidity at 6-h intervals with a horizontal resolution of $0.75^{\circ} \times 0.75^{\circ}$ during 1979-2016 were obtained from the ERA-Interim reanalysis data (http://apps.ecmwf.int/datasets/) produced by the European Centre for Medium-Range Weather Forecasts (ECMWF; Dee et al. 2011). The 6-h precipitation data from the reanalysis were converted to 24 -h precipitation amount from 2000 Beijing time (BJT) of the previous day to 2000 BJT of the current day. Because BJT is $8 \mathrm{~h}$ ahead of Coordinated Universal Time (UTC), the moisture fluxes were calculated by averaging five 6-h times of the ERA-Interim reanalysis data: 1200 (2000) and 1800 (0200) UTC (BJT) of the previous day and 0000 (0800), 0600 (1400), and 1200 (2000) UTC (BJT) of the current day. Summer over NC is defined as June-July-August (JJA).

\subsection{Methodology}

\subsubsection{Extreme precipitation days}

The widely used percentile threshold value is considered to be more appropriate for studying extreme precipitation over mainland China than a fixed criterion (Zhai et al. 2005; Luo et al. 2016). This method supports direct comparison of extreme precipitations in different regions (Tian and Fan 2013). In the present study, the 95th percentile of each station in NC was first calculated. The mean of all the 95th percentiles was then taken as the threshold to select extreme precipitation days for $\mathrm{NC}$, based on the average daily precipitation for NC.

\subsubsection{Moisture flux}

The zonal ( $q u)$ and meridional $(q v)$ components of the column-integrated moisture flux are described as follows (Zhao et al. 2018a, b):

$\mathrm{qu}(x, y, t)=\frac{1}{g} \int_{p_{t}}^{p_{s}} q(x, y, p, t) u(x, y, p, t) d p$,

$\mathrm{qv}(x, y, t)=\frac{1}{g} \int_{p_{t}}^{p_{s}} q(x, y, p, t) v(x, y, p, t) d p$,

where $u$ and $v$ are the zonal and meridional winds, respectively, $g$ is gravitational acceleration, and $q$ is specific humidity. $P_{t}$ is the pressure at the top of the troposphere. Because most atmospheric water vapor resides below $300 \mathrm{hPa}$, herein $300 \mathrm{hPa}$ is regarded as the level of top pressure, and hence the specific humidity $q$ at top pressure $p_{t}$ is near zero (Zhang et al. 2010; Zhao et al. 2013; Sahin et al. 2015). Considering that the complex topography over NC can interfere with the moisture transport of extreme precipitation (Sun et al. 2015), $p_{s}$ is defined as surface pressure.

\subsubsection{Moisture budget}

To identify the most relevant moisture transport processes that contribute to extreme precipitation occurrence, each term in the moisture budget equation is computed (Yoon and Chen 2005; Chen and Tomassiniand 2015):

$$
-\left\langle\overline{\frac{\partial q}{\partial t}}\right\rangle-\langle\overline{\nabla \cdot(\vec{v} q)}\rangle-\left\langle\overline{\frac{\partial}{\partial p}(\omega q)}\right\rangle=\bar{P}-\bar{E},
$$

where $P$ is precipitation, $E$ is evaporation, $q$ is specific humidity, $\overrightarrow{\mathrm{v}}$ is horizontal vector, and $\nabla=\vec{i} \frac{\partial}{\partial x}+\vec{j} \frac{\partial}{\partial y}$ is the horizontal gradient operator. Bars denote the temporal mean, and $\langle\cdot\rangle$ indicates vertical integrals $\int_{p_{t}}^{p_{s}}(\cdot) d p / g$. The first item on the left side $-\left\langle\frac{\partial q}{\partial t}\right\rangle$ denotes the local rate of change in specific humidity. The second item on the left side of the equation $-\langle\overline{\nabla \cdot(\vec{v} q)}\rangle$ denotes horizontal moisture flux convergence (MFC), which is the net moisture transport gain or loss caused by inflow and outflow of an atmospheric column. The third item on the left side of the equation $-\left\langle\frac{\partial}{\partial p}(\omega q)\right\rangle$ represents vertically integrated MFC. Pressure velocity $\omega$ is 
Fig. 1 a WRF model simulation domain setup. The blue dashed box denotes the NC region. b Spatial distribution of the 139 observational stations (blue dots) over North China (NC; red box; $35^{\circ}-42^{\circ} \mathrm{N}$, $\left.110^{\circ}-120^{\circ} \mathrm{E}\right)$. Color shading denotes terrain height $(\mathrm{m})$. c Spatial distribution of the 95th percentile threshold daily mean extreme precipitation amount (color shading; $\mathrm{mm}$ ) over $\mathrm{NC}$ in summers during 1979-2016. $\mathbf{d}$ Zonal and $\mathbf{e}$ is the meridional vertical cross-section of terrain height (m) over NC (a)

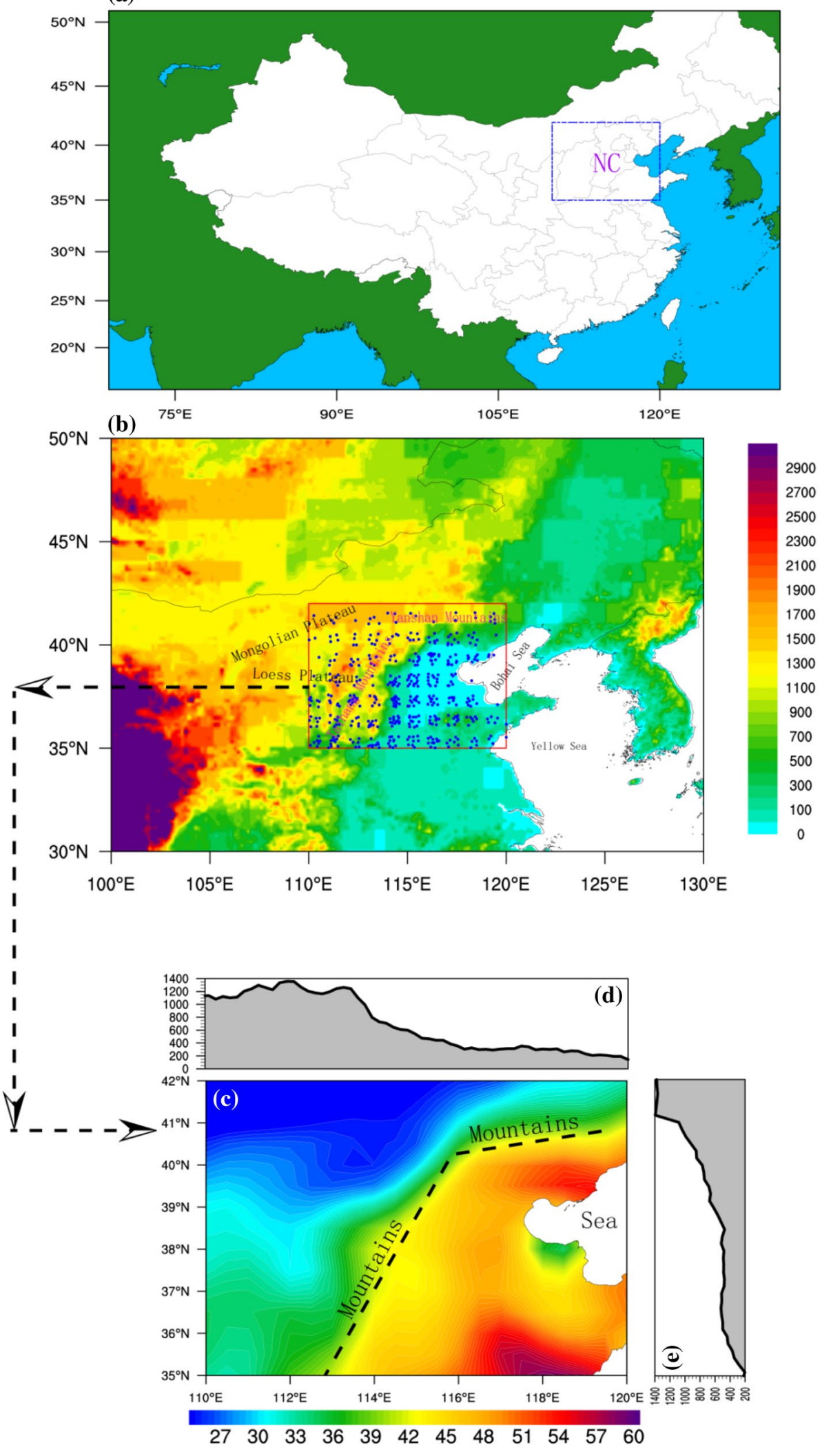


assumed to be zero at the surface $p_{s}$ and at the moisture upper boundary $p_{t}$.

\subsubsection{Moisture flux convergence (MFC)}

Assuming zero values of $q$ at the top level $p_{t}$ and of $\omega$ at $p_{s}$ and $p_{t}$, the third term on the left side $-\left\langle\frac{\partial}{\partial p}(\omega q)\right\rangle$ of Eq. (3) is taken to be zero (Chou and Lan 2012). As $-\left\langle\frac{\partial q}{\partial t}\right\rangle$ contributes little to precipitation, this term can also be neglected (Zhu 2007). Therefore, the moisture budget of summer extreme precipitation over $\mathrm{NC}$ depends mainly on the change in horizontal MFC, which is proportional to the vertically integrated product of specific humidity and horizontal mass convergence through the troposphere.

The horizontal MFC is often simply referred to as MFC (Banacos and Schultz 2005). From now on, MFC is defined as the horizontal moisture flux convergence integrated between the surface $p_{s}$ and upper boundary $p_{t}$ at $300 \mathrm{hPa}$. To further quantify the aggregation and convergence of moisture over NC, MFC is decomposed as follows (Zomeren and Delden 2007):

$-\frac{1}{\mathrm{~g}} \int_{p_{t}}^{p_{s}} \nabla \cdot(q \vec{v}) d p=-\frac{1}{g} \int_{p_{t}}^{p_{s}} q \nabla \cdot \vec{v} d p-\frac{1}{g} \int_{p_{t}}^{p_{s}} \vec{v} \cdot \nabla q d p$,

where $-\frac{1}{g} \int_{p_{t}}^{p_{s}} q \nabla \cdot \vec{v} d p$ is the moisture convergence term representing the vertically integrated product of horizontal wind convergence, which is related to forced lifting. The second term $-\int_{p_{t}}^{p_{s}} \vec{v} \cdot \nabla q d p$ is proportional to the moisture advection term, and referred to as "moisture pooling".

\subsubsection{Design of numerical simulations}

The weather and research forecasting (WRF) model version 3.4.1 (Skamarock and Klemp 2008; Yu 2013; Zhong and Yang 2015) is a fully compressible and non-hydrostatic atmospheric model, and was used to examine MFC changes due to a change in topography, forcing on the orographic effect on extreme precipitation over NC. Six historical extreme precipitation days over $\mathrm{NC}$ were randomly selected from the summer of 1979-2016 (Table 1) for the simulations.

The domain configuration uses one-way interactive nested inner grids of D01 (Fig. 1a). The central point of the simulation is located at $35^{\circ} \mathrm{N}$ and $100^{\circ} \mathrm{E}$. The horizontal grid resolution is $30 \mathrm{~km}$ with $201 \times 141$ grid points. There are 38 unevenly spaced full sigma levels in the vertical dimension with the top level at $50 \mathrm{hPa}$. A sensitivity test is designed by removing the topography within the $\mathrm{NC}$ area of $110^{\circ}-120^{\circ}$ E, $35^{\circ}-42^{\circ} \mathrm{N}$, predominantly covering the Yanshan-Taihang
Table 1 Six selected extreme precipitation days over NC in summers from 1979 to 2016 and their mean 24-h precipitation based on all the available station data

\begin{tabular}{llll}
\hline Year & Date & $\begin{array}{l}\text { Precipitation } \\
(\mathrm{mm})\end{array}$ & $\begin{array}{l}\text { Ranking of precipitation } \\
\text { intensity in 38 extreme } \\
\text { days }\end{array}$ \\
\hline 1981 & 20 Jun & 24.5 & 25 \\
1995 & 25 Jul & 29.6 & 15 \\
1995 & 06 Aug & 26.8 & 20 \\
2005 & 16 Aug & 23.6 & 30 \\
2009 & 08 Jul & 23.4 & 31 \\
2011 & 02 Jul & 24.4 & 27 \\
\hline
\end{tabular}

The ranking starts from the lowest to the highest intensity

Mountains. Both the control and sensitivity simulations used a time step of $60 \mathrm{~s}$. The output interval of the WRF model is $1 \mathrm{~h}$. Initial conditions and boundary data every $6 \mathrm{~h}$ were taken from the ERA-Interim reanalysis data, which have a horizontal resolution of $0.75^{\circ} \times 0.75^{\circ}$. The simulations begin $12 \mathrm{~h}$ before the occurrence of extreme precipitation on each of the six selected days.

The performance of different physical schemes employed in the WRF simulation for extreme precipitation events over $\mathrm{NC}$ has been documented in the literature. The Kain-Fritsch (KF) cumulus scheme includes convection as well as relevant ascending and downward motions, which hold a large amount of mass, thermal energy, and moisture (Kain and Fritsch 1993). Ma et al. (2012) reported that the WRF Single-Moment 6-Class Microphysics Scheme (WSM6) performed satisfactorily in simulations of the location and intensity of a rainstorm event over NC during 18-19 August 2010 when the horizontal resolution was set to $4 \mathrm{~km}$. Zhao et al. (2010) suggested that parameterizations of the KF cumulus scheme, the Yonsei University planetary boundary layer (PBL) scheme, and the Dudhia shortwave radiative scheme could simulate extreme precipitation over NC well. The KF cumulus parameterization scheme, Yonsei University PBL, Rapid Radiative Transfer Model (RRTM) scheme for long wave radiation, Dudhia scheme for shortwave radiation, and Noah land-surface scheme were also chosen to capture a summer rainstorm and its related moisture transport over NC during 2010 (Wang et al. 2014). Tian et al. (2017) simulated precipitation in the northern China with the Noah land-surface model (LSM) scheme. Based on these previous studies, the WRF model physics packages used in this work are decided and listed in Table 2.

\subsubsection{Atmospheric apparent heat source}

To further explore terrain effect on moisture transport and precipitation, the atmospheric apparent heat source $\left(Q_{1}\right)$ was calculated. By comparing $\mathrm{Q}_{1}$ in the control and sensitivity 
Table 2 Physical parameterization options chosen for the WRF model

\begin{tabular}{ll}
\hline Physical parameter & Option selected \\
\hline Microphysics & WSM6 \\
Shortwave radiation & Dudhia scheme \\
Longwave scheme & RRTM scheme \\
Cumulus parameterization & Kain-Fritsch scheme \\
Boundary layer scheme (PBL) & Yonsei University scheme \\
Land-surface model (LSM) & Unified Noah land-surface scheme \\
\hline
\end{tabular}

tests, we try to quantify the atmospheric heating affected by terrain. The equation for $\mathrm{Q}_{1}$ is as follows:

$\mathrm{Q}_{1}=\mathrm{C}_{\mathrm{p}}\left(\frac{\partial T}{\partial t}+\overrightarrow{\mathrm{V}} \cdot \nabla \mathrm{T}+\omega\left({\frac{\mathrm{P}}{\mathrm{P}_{0}}}^{\mathrm{k}}\right) \frac{\partial \theta}{\partial \mathrm{P}}\right)$

where $\vec{V}$ and $\omega$ represent the horizontal wind fields and vertical motion. The $\mathrm{T}$ denotes the temperature. $\mathrm{p}_{0}$ is set to be $850 \mathrm{hPa}$ at here. $\theta$ is the potential temperature and Cp represents the specific heat constant. The constant $\mathrm{k}=0.286$. The vertically integrated $\mathrm{Q}_{1}$ equation can be written as:

$\left\langle Q_{1}\right\rangle=L P+S+\left\langle Q_{R}\right\rangle$

where $\mathrm{L}$ means the latent heat of condensation and $\mathrm{q}$ denotes the specific humidity. P represents the precipitation and $\mathrm{S}$ denotes the surface sensible heat flux. The radiative heating is denoted as $\left\langle Q_{R}\right\rangle$. The $\mathrm{Q}_{1}$ in whole column represents the sum of latent heat and surface sensible heat fluxes as well as the radiative heating.

\section{Results and discussion}

\subsection{Extreme precipitation over NC and related moisture transport}

NC is surrounded by the Yanshan and Taihang Mountains along the eastern margins of the Mongolian Plateau and the Loess Plateau to the north and west, respectively. This region faces the Bohai Sea to the east (Fig. 1b), and is mainly subject to the influence of humid monsoon climate (Ding et al. 2010). The summer mean value of the 95th percentile threshold daily extreme precipitation across the entire $\mathrm{NC}$ is estimated to be $22.7 \mathrm{~mm}$. Thus, an extreme precipitation day over $\mathrm{NC}$ is defined when the regional mean of daily precipitation over $\mathrm{NC}$ is greater than $22.7 \mathrm{~mm}$. With this definition, totally 38 extreme precipitation days over NC were selected from the summers during 1979 and 2016.

The Taihang and Yanshan Mountains, with altitudes above about $1000 \mathrm{~m}$, divide daily mean extreme precipitation across $\mathrm{NC}$ in summer into intense precipitation over the eastern coastal areas and relatively weak precipitation over the inland western areas (Fig. 1c). In particular, daily mean extreme precipitation is most intense over the southeastern $\mathrm{NC}$, with values up to $\sim 55 \mathrm{~mm}$. This result is consistent with the spatial pattern documented by Zhao et al. (2019b). This feature may have been caused by the foehn effect along the foot of the Taihang and Yanshan mountains and the humid airflow over eastern NC from the ocean (Fig. 1d, e). This spatial pattern of daily mean extreme precipitation over NC indicates the linkage between extreme precipitation and the surrounding topography, which implies that the most intense extreme precipitation is likely to occur over the eastern part of $\mathrm{NC}$, along the steepest slopes in the region.

Moisture transport plays a key role in summer extreme precipitation (Zhao et al. 2016). We first present the climatological mean moisture fluxes in summer during 1979-2016 to illustrate the general moisture transport background over NC (Fig. 2a). South-westerly winds bring moisture to NC, derived mainly from the Bay of Bengal and the South China Sea. The composite column-integrated moisture transport for the 38 extreme precipitation days is then explored. There are two moisture transport pathways for the summer extreme precipitation: the westerly pathway along the northern periphery of the Tibetan Plateau (TP), and the southerly pathway east of the TP that transports abundant moisture primarily from the Bay of Bengal, the South China Sea, and the tropical western Pacific (Fig. 2b).

Comparisons of moisture transport between the climatological mean and extreme precipitation days over $\mathrm{NC}$ reveal some interesting differences. Due to the prevailing anticyclone over the western North Pacific, moisture transport from the tropical western Pacific towards NC during summer extreme precipitation days is more evident than in the climatological mean. The westerly pathway prevails over NC during extreme precipitation days. Most extreme precipitation events were caused by atmospheric circulation anomalies (Tian and Fan 2013). In fact, Hu et al. (2018) reported that summer extremes over mainland China are driven primarily by anomalous circulations, which prompts us to analyze the composite anomalies of column-integrated moisture transport favoring extreme precipitation over NC. A large amount of moisture originates mainly from the westerlies, the South China Sea, and the tropical western Pacific under the combined effects of the anomalous anticyclone over the western North Pacific and the cyclonic anomaly over the South China Sea. It becomes clear that the westerly pathway and the southerly moisture transport pathway are critical to summer extreme precipitation in the region (Fig. 2c).

Moisture transport towards NC during extreme precipitation days is much stronger than in the climatological summer mean. Notably, extreme precipitation days witness that the confluent moisture over NC tends to be transported over the relatively flat plains rather than the neighboring elevated terrains of the Yanshan and Taihang Mountains. 
Fig. 2 a Climatologically column-integrated moisture flux (vectors; $10^{2} \mathrm{~kg} \mathrm{~m}^{-1} \mathrm{~s}^{-1}$ ) in summer during 1979-2016. b Composite column-integrated moisture flux (vectors; $10^{2} \mathrm{~kg} \mathrm{~m}^{-1} \mathrm{~s}^{-1}$ ) for the 38 summer extreme precipitation days during 1979-2016. c The difference of the columnintegrated moisture flux (vectors; $10^{2} \mathrm{~kg} \mathrm{~m}^{-1} \mathrm{~s}^{-1}$ ) between summer extreme precipitation and climate state. The purple rectangle indicates the $\mathrm{NC}$ region and the grey shading represents terrain height (m). Red dots denote the anomalous column-integrated moisture flux exceeding the $90 \%$ confidence level of $t$ test. The green line is the 3000 m elevation contour

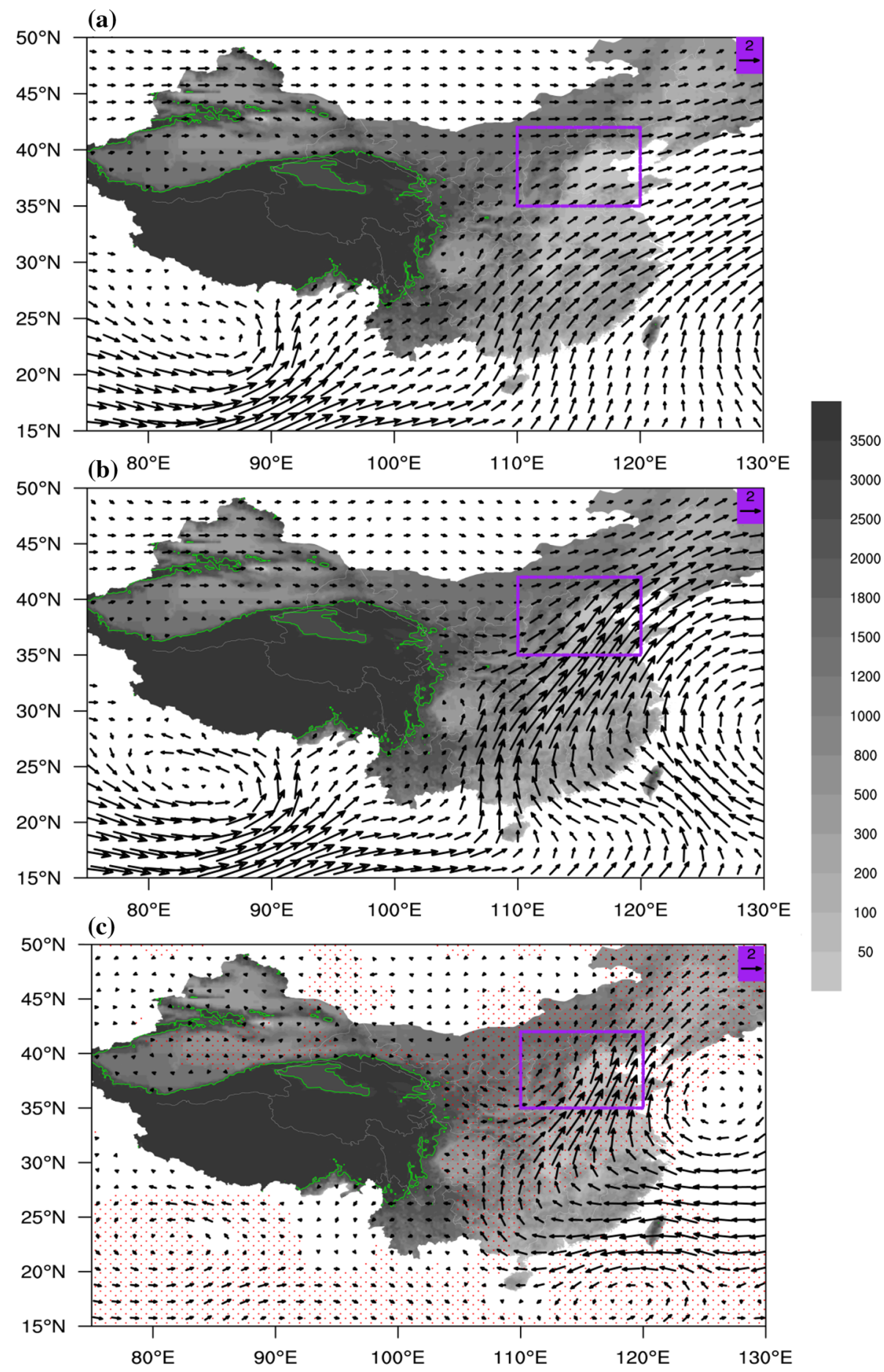

To quantify the effect of moisture transport that facilitates extreme precipitation over $\mathrm{NC}$, we calculate the columnintegrated moisture flux across each boundary of NC. During the extreme precipitation days, $\mathrm{NC}$ is under the control of westerlies and the southerly moisture transport pathway with moisture sources from the Bay of Bengal, South China Sea, and the western North Pacific. Four boundaries of NC were set to investigate the quantitative features of moisture transport. There is a predominant southerly moisture influx of $311.8 \mathrm{~kg} \mathrm{~m}^{-1} \mathrm{~s}^{-1}$ into $\mathrm{NC}$ along the southern boundary and a secondary influx of $107.9 \mathrm{~kg} \mathrm{~m}^{-1} \mathrm{~s}^{-1}$ across the western boundary due to mid-latitude westerlies. In addition, the outward moisture flux across the eastern boundary is $206.9 \mathrm{~kg} \mathrm{~m}^{-1} \mathrm{~s}^{-1}$ and across the northern boundary is $76.0 \mathrm{~kg} \mathrm{~m}^{-1} \mathrm{~s}^{-1}$, as shown in Fig. 3a. The moisture influx across the southern boundary is stronger than that across 


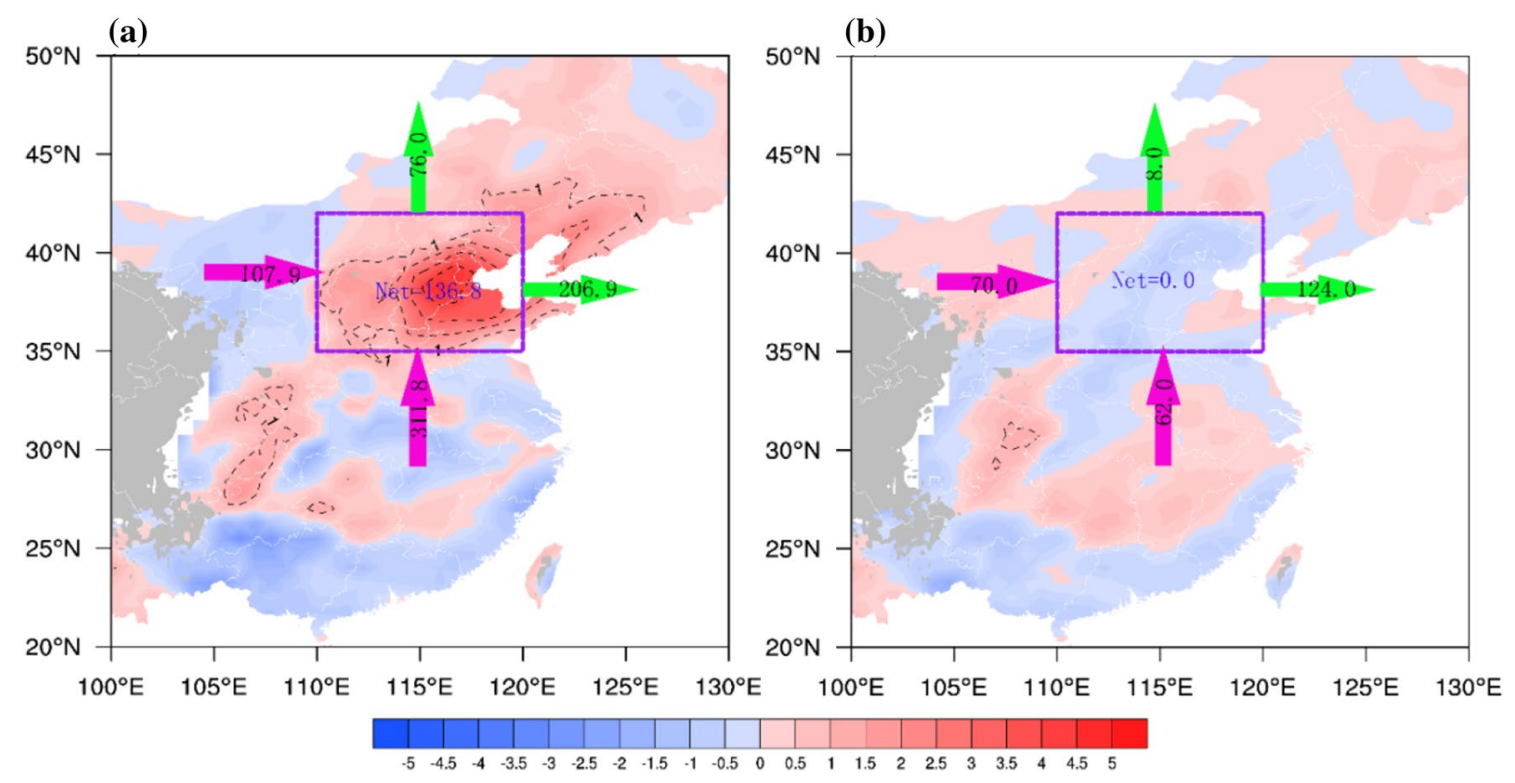

Fig. 3 a Composite moisture budget for the 38 summer extreme precipitation days over NC for 1979-2016. The purple box denotes the $\mathrm{NC}$ region. b Climatological summer mean moisture budget over NC for 1979-2016. The red shading denotes MFC and the blue shading represents moisture flux divergence $\left(10^{-5} \mathrm{~kg} \mathrm{~m}^{-2} \mathrm{~s}^{-1}\right)$. The dashed

the western boundary, while the outgoing moisture flux is larger at the eastern boundary than at the northern boundary than at the northern boundary. The zonal budget of moisture flux is negative as the influx along the western boundary is less than the outgoing flux via the eastern boundary. On the contrary, meridional flow evidently brings moisture into $\mathrm{NC}$ because the influx across the southern boundary is much stronger than the outflow through the northern boundary. The meridional surplus is distinctly higher than the zonal deficit, consistent with previous literature (Wang et al. 2014). Therefore, NC has a conspicuous maximum of MFC exceeding approximately $4 \times 10^{-5} \mathrm{~kg} \mathrm{~m}^{-2} \mathrm{~s}^{-1}$ (red shading in Fig. 3a) and the corresponding net moisture budget is a gain of $136.8 \mathrm{~kg} \mathrm{~m}^{-1} \mathrm{~s}^{-1}$. The positive net moisture flux certainly favors the generation of extreme precipitation.

In the summer climatology of MFC during 1979-2016, there are two moisture influx channels at the southern $\left(62.0 \mathrm{~kg} \mathrm{~m}^{-1} \mathrm{~s}^{-1}\right)$ and western $\left(70.0 \mathrm{~kg} \mathrm{~m}^{-1} \mathrm{~s}^{-1}\right)$ boundaries, and both the eastern $\left(124.0 \mathrm{~kg} \mathrm{~m}^{-1} \mathrm{~s}^{-1}\right)$ and northern $\left(8.0 \mathrm{~kg} \mathrm{~m}^{-1} \mathrm{~s}^{-1}\right)$ boundaries are export channels (Fig. 3b). The incoming moisture transport at the southern and western boundaries shares similar intensity, whereas the outgoing moisture transport along the eastern boundary is much stronger than that at the northern boundary. At the same time, the zonal budget of moisture remains negative while the meridional surplus remains significant, broadly consistent with the zonal and meridional net budgets of moisture during extreme precipitation days. Consequently, the contour line denotes the value of MFC exceeding $1.0 \times 10^{-5} \mathrm{~kg} \mathrm{~m}^{-2}$ $\mathrm{s}^{-1}$. The thick colored arrows and associated values represent the direction and intensity of moisture flux at each boundary $\left(\mathrm{kg} \mathrm{m}^{-1}\right.$ $\mathrm{s}^{-1}$ ). "Net" denotes the net moisture supply to the box. The grey shading denotes part of the Tibetan Plateau (TP)

climatological meridional surplus just balances the zonal deficit and the net budget of climatological summer mean moisture over NC tends to approach zero.

The above analysis indicates that NC is a prominent moisture sink during summer extreme precipitation days, unlike in the climatological summer mean. In addition, the MFC maximum core, the pronounced moisture fluxes and the striking extreme precipitation zone over NC are all anchored to the east of the surrounding steep slopes of the Yanshan and Taihang Mountains.

As a crucial term in the moisture budget, the vertically integrated MFC is a useful predictor of precipitation connected with synoptic-scale systems. Further, it has been used to forecast convective initiation at mid-latitudes in recent decades (e.g., Banacos and Schultz 2005). Previous studies inferred that the changes in MFC could be divided into two contributions from (1) wind convergence as a result of changes in circulation (Seo et al. 2013; Freychet et al. 2015), and (2) advection due to changes in humidity gradients. Figure 4 shows the two terms of the vertically integrated MFC in Eq. (4) for extreme precipitation days and the climatological summer mean. During the extreme precipitation days, the enhanced moisture transport brought more water vapor to NC from the tropical oceans and via westerlies (Fig. 2b), forming the maximum MFC core inside NC (Fig. 3a). The significant increase in $\mathrm{MFC}$ over the entire $\mathrm{NC}$ region is mainly attributable to enhancements in wind convergence, and the advection term is only effective over the eastern $\mathrm{NC}$ 
(a)

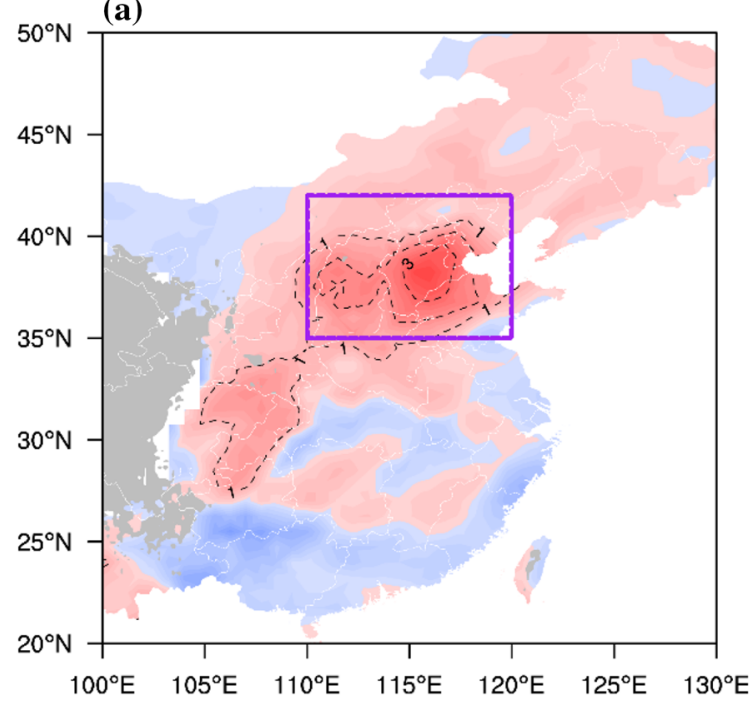

(c)

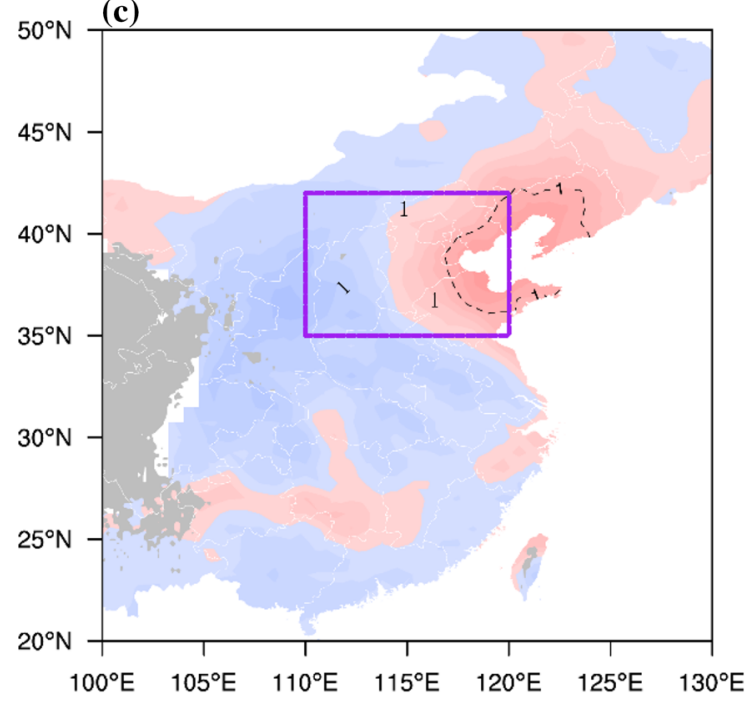

(b)

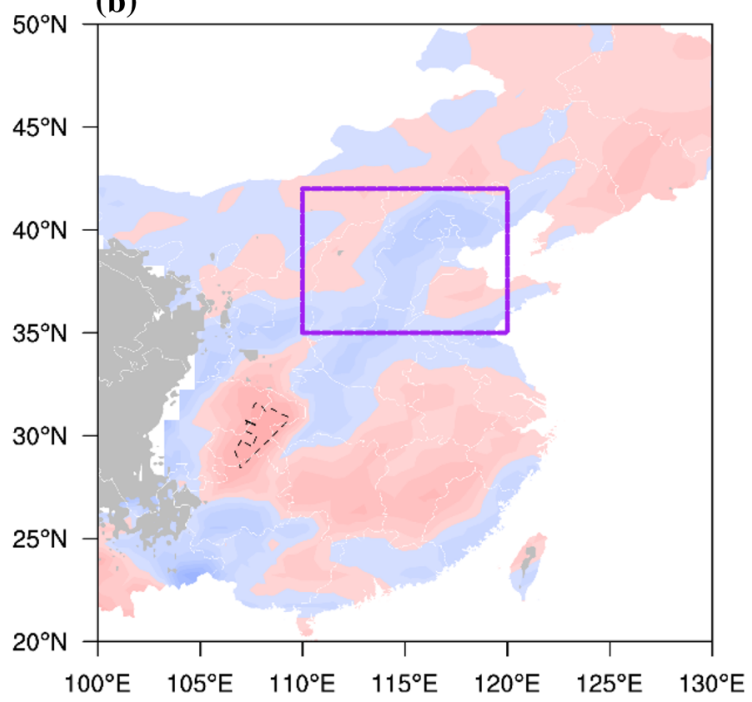

$50^{\circ} \mathrm{N}$

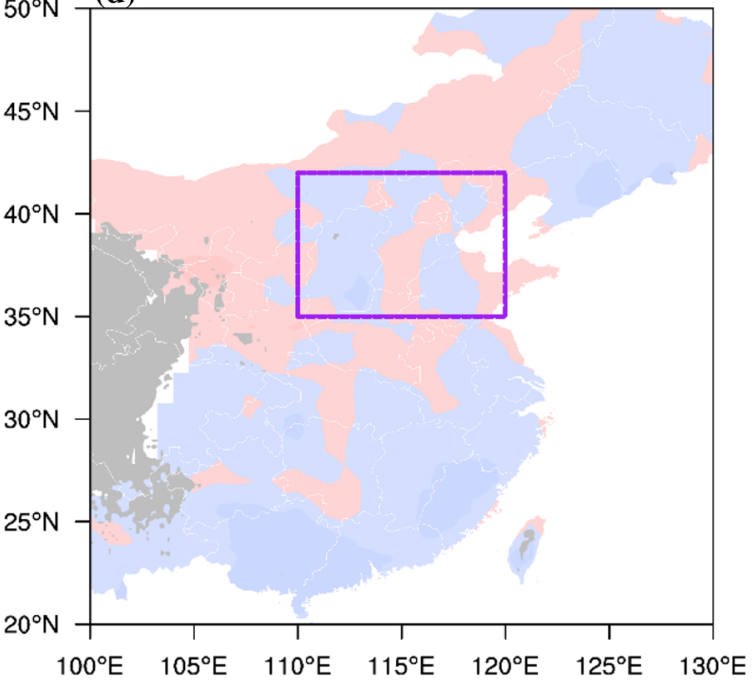

$\begin{array}{llllllllllllllllllllll}-5 & -4.5 & -4 & -3.5 & -3 & -2.5 & -2 & -1.5 & -1 & -0.5 & 0 & 0.5 & 1 & 1.5 & 2 & 2.5 & 3 & 3.5 & 4 & 4.5 & 5\end{array}$

Fig. 4 Wind convergence term (color shading, unit: $10^{-5} \mathrm{~kg} \mathrm{~m}^{-2} \mathrm{~s}^{-1}$ ) of the MFC over NC for a the 38 summer extreme precipitation days and $\mathbf{b}$ the climatological summer mean. $\mathbf{c}, \mathbf{d}$ As for $\mathbf{a}$ and $\mathbf{b}$, but for

plain (Fig. 4a, c). Quantitative analysis shows that $90 \%$ in the increase of $1.54 \times 10^{-5} \mathrm{~kg} \mathrm{~m}^{-2} \mathrm{~s}^{-1}$ in MFC comes from an enhancement of $1.39 \times 10^{-5} \mathrm{~kg} \mathrm{~m}^{-2} \mathrm{~s}^{-1}$ in wind convergence and only $10 \%$ from an increase of $1.5 \times 10^{-6} \mathrm{~kg} \mathrm{~m}^{-2} \mathrm{~s}^{-1}$ in advection (Table 3 ). Thus, the intensified extreme precipitation over $\mathrm{NC}$ is mainly caused by reinforced convergence of horizontal winds.

Note that the climatological summer mean MFC is slightly negative over NC. Compared with the case for the extreme precipitation days, and both the climatological wind convergence and advection terms are small. The reduction of the climatological summer mean MFC to $1.3 \times 10^{-6} \mathrm{~kg} \mathrm{~m}^{-2}$ $\mathrm{s}^{-1}$ in this region corresponds primarily to the sharply the moisture advection term. The purple box denotes the NC region. The grey shading indicates the part of the TP

Table 3 Contributions of wind convergence and advection to the MFC over the whole NC (unit: $10^{-5} \mathrm{~kg} \mathrm{~m}^{-2} \mathrm{~s}^{-1}$ )

\begin{tabular}{lcrr}
\hline & MFC $-\nabla \cdot(\mathrm{q} \vec{V})$ & $\begin{array}{l}\text { Convergence } \\
-\mathrm{q} \nabla \cdot \vec{V}\end{array}$ & $\begin{array}{l}\text { Advection } \\
-\vec{V} \cdot \nabla q\end{array}$ \\
\hline Extreme state & 1.54 & $1.39(90.0 \%)$ & $0.15(10.0 \%)$ \\
Climate state & -0.13 & $-0.12(92.3 \%)$ & $-0.01(7.7 \%)$ \\
\hline
\end{tabular}

decreased convergence term $1.2 \times 10^{-6} \mathrm{~kg} \mathrm{~m}^{-2} \mathrm{~s}^{-1}$ accounting for $92.3 \%$ and the slightly reduced advection term $1.0 \times 10^{-7} \mathrm{~kg} \mathrm{~m}^{-2} \mathrm{~s}^{-1}$ only accounting for $7.7 \%$ (Table 3 ), demonstrating the dominance of wind convergence term in 
terms of the MFC that links with the summer mean precipitation over NC.

The summer precipitation over NC on both extreme precipitation days and other days heavily rely on horizontal wind convergence. The intensified convergence leads to greater MFC and consequently heavy summer precipitation over NC.

The above results provide a quantitative understanding of the spatial pattern of extreme precipitation over NC and associated moisture transport, and imply a role of the adjacent elevated terrain on extreme precipitation and associated moisture transport. Many studies have discussed possible mechanism by which the adjacent topography affects summer precipitation in NC and beyond. He and Zhang (2010) attributed warm-season precipitation over NC to the upward and downward branches of a solenoidal circulation between mountain ranges and plains. Liu et al. (2009) proposed that

(a)

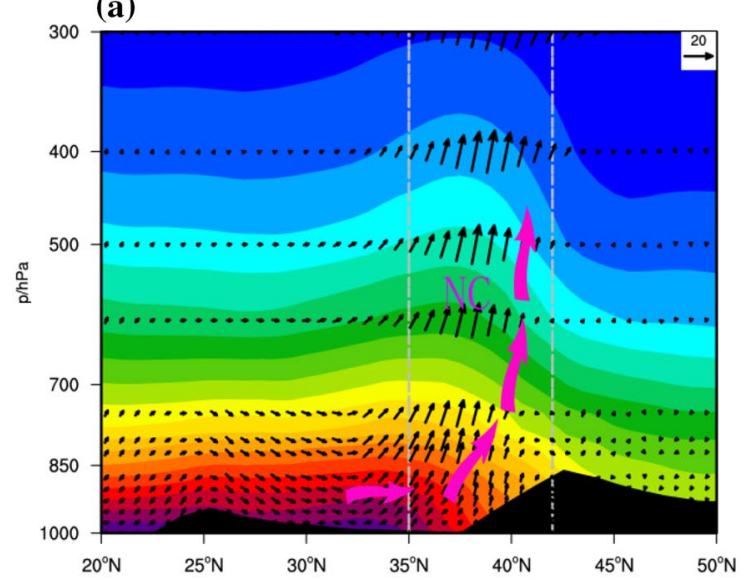

(c)

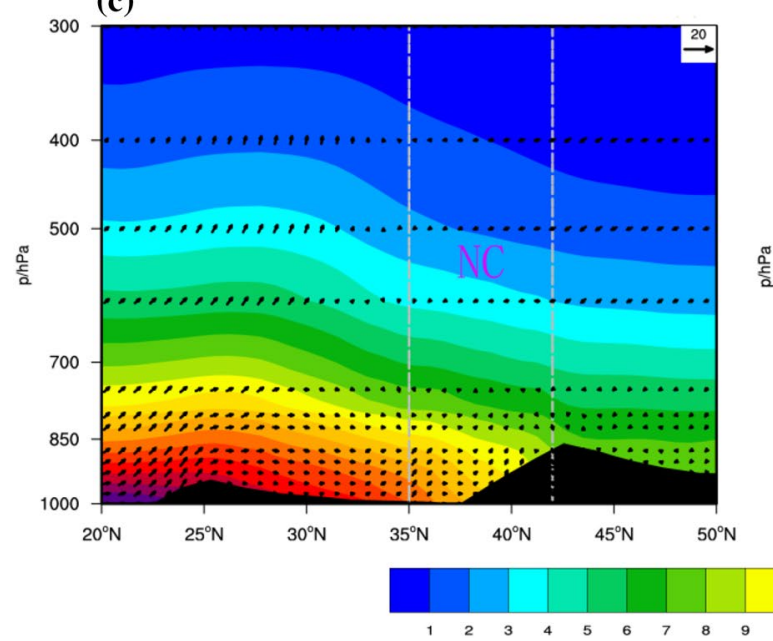

Fig. 5 Vertical cross-sections of a $v$ (vectors; $\mathrm{m} \mathrm{s}^{-1}$ ), $\omega$ (vectors; $-10^{-2} \mathrm{~Pa} \mathrm{~s}^{-1}$ ), and humidity (color shading; $\mathrm{kg} \mathrm{kg}^{-1}$ ) showing the meridional average over $\mathrm{NC}$ for the 38 extreme precipitation days and b $u$ (vectors; $\mathrm{m} \mathrm{s}^{-1}$ ), $\omega$ (vectors; $-10^{-2} \mathrm{~Pa} \mathrm{~s}^{-1}$ ), and humidity (color shading; $\mathrm{kg} \mathrm{kg}^{-1}$ ) showing the zonal average over $\mathrm{NC}$ for the 38 the distinct precipitation contrast between the central TP and the periphery is caused by orographic effects on regional convection, implying a convergence-divergence pattern near the edge of the TP. To visualize the influence of the neighboring elevated terrain on extreme precipitation and related moisture transport, vertical cross-sections of moisture and vertical velocity for summer extreme precipitation days and the climatological summer mean are shown in Fig. 5.

Comparing the vertical cross-sections for extreme precipitation days with that for climatological mean days, the upward airflow during extreme precipitation days is more vigorous than that of the climatological state in both meridional and zonal directions. An obvious humidity tongue is observed over $\mathrm{NC}$ during extreme precipitation days (Fig. 5a, b), with higher humidity than in the climatological summer mean (Fig. 5c, d) at the same level. Note that the remarkable humidity tongue and strong ascending

(b)

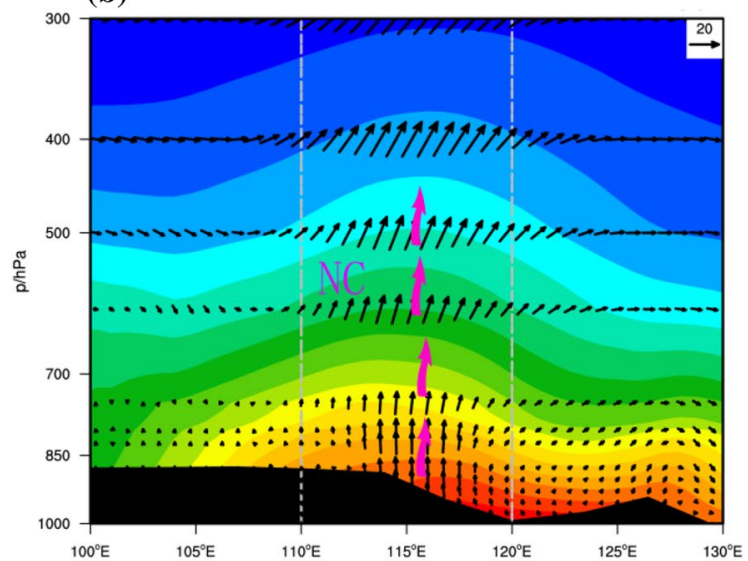

(d)

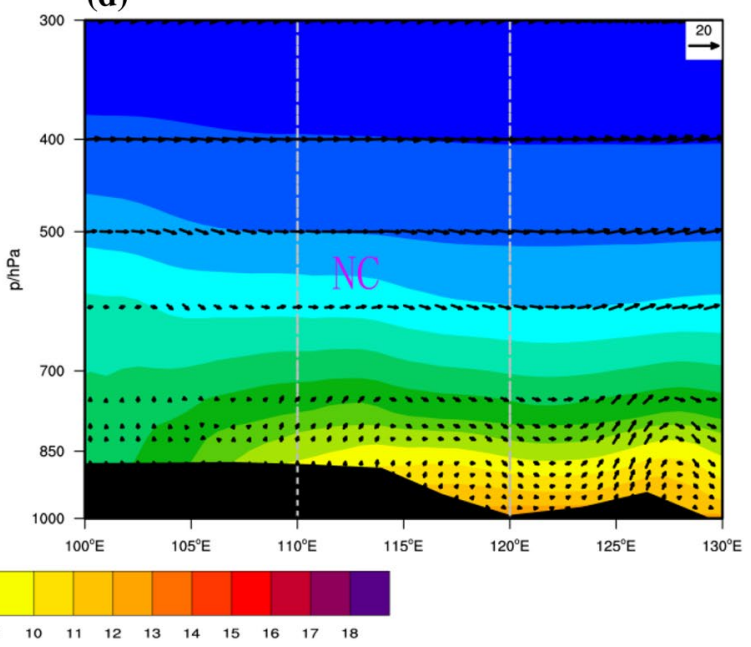

extreme precipitation days. c, $\mathbf{d}$ As for $\mathbf{a}$ and $\mathbf{b}$, but for climatological summer mean during 1979-2016. The black shading shows the terrain. NC lies within the grey dashed lines. The meridional and zonal section-cross along the average longitude $\left(110^{\circ}-120^{\circ} \mathrm{E}\right)$ and average latitude $\left(35^{\circ}-42^{\circ} \mathrm{N}\right)$ of $\mathrm{NC}$ region 
motion conducive to extreme precipitation tend to occur near the steep slopes of terrain over NC, which confirms the important role of the adjacent elevated terrain in enhancing extreme precipitation over NC.

\subsection{Difference in moisture transport associated with summer extreme precipitation between the control and sensitivity tests}

The above analysis has revealed the important effect of the surrounding topography on extreme precipitation over NC. However, the exact contribution of elevated terrain to extreme precipitation and the details of the associated processes require deeper insight and clarification. To examine the influence of the adjacent elevated terrain on extreme precipitation over $\mathrm{NC}$, the control simulation retains the terrain heights over $\mathrm{NC}$ (Fig. 6a), whereas the terrain height is removed over NC in the sensitivity test (Fig. 6b). To reduce the sudden change of the elevation on the boundaries of $\mathrm{NC}$ in the sensitivity test, the boundary height was set to be half of those from the control run. Within the boundaries, the elevations were all set to zero.

Figure 6 shows the composites of the control and sensitivity tests for the six selected extreme precipitation days (Table 1). Precipitation intensity and spatial distribution over NC in the control simulation have similar patterns to the observed precipitation. The largest precipitation amount is anchored over the Taihang Mountains in both control and observations, but the precipitation peak in the control simulation is slightly weaker than that observed (Fig. 6c, e). Moreover, compared with the observed, the location of central precipitation region in the control test is in higher latitude (Fig. 6c, e). In contrast, precipitation intensity in the sensitivity test is significantly weaker than that observed, especially over the Taihang Mountains. Compared with the control test, the largest value center in the sensitivity test is missing (Fig. 6d). The rain band in the sensitivity is located in the plain area, which is basically along the Taihang mountains (as shown in Fig. 1). The neighboring elevated terrain is found to favor summer extreme precipitation over NC. Without the terrain, precipitation intensity over NC would be weakened dramatically.

We next assess the composites of column-integrated moisture transport for summer extreme precipitation days with and without the orographic effect. In the control and sensitivity tests, the composite column-integrated moisture is transported along the eastern region of the TP from the tropical oceans including the western Pacific, the South China Sea, and the Bay of Bengal, and by the westerlies along the north margin of the TP. In the control simulation, inflows of moisture cross the southern $\left(377.3 \mathrm{~kg} \mathrm{~m}^{-1} \mathrm{~s}^{-1}\right)$ and western $\left(87.4 \mathrm{~kg} \mathrm{~m}^{-1} \mathrm{~s}^{-1}\right)$ boundaries of the $\mathrm{NC}$ region, and moisture flows out through the eastern $\left(249.8 \mathrm{~kg} \mathrm{~m}^{-1} \mathrm{~s}^{-1}\right)$ and northern $\left(51.8 \mathrm{~kg} \mathrm{~m}^{-1} \mathrm{~s}^{-1}\right)$ boundaries. The incoming moisture transport at the southern boundary is much larger than that at the western boundary, while the outgoing moisture transport is larger at the eastern boundary, consistent with our diagnosed results from the reanalysis. The corresponding net moisture transport in the control simulation is a gain of $163.1 \mathrm{~kg} \mathrm{~m}^{-1} \mathrm{~s}^{-1}$ (Fig. 7a). In the sensitivity test, the moisture influx over $\mathrm{NC}$ includes one channel across the southern boundary of $356.9 \mathrm{~kg} \mathrm{~m}^{-1} \mathrm{~s}^{-1}$ and another across the western boundary of $70.9 \mathrm{~kg} \mathrm{~m}^{-1} \mathrm{~s}^{-1}$. The moisture influx across both the two boundaries in the sensitivity test is weaker than in the control simulation. The outgoing moisture flux across the eastern boundary is $235.4 \mathrm{~kg} \mathrm{~m}^{-1} \mathrm{~s}^{-1}$ and that across the northern boundary is $55.4 \mathrm{~kg} \mathrm{~m}^{-1} \mathrm{~s}^{-1}$. The net surplus of moisture transport in the sensitivity test is $137.0 \mathrm{~kg} \mathrm{~m}^{-1} \mathrm{~s}^{-1}$ (Fig. 7b).

The entire NC has a remarkable maximum of MFC above $4 \times 10^{-5} \mathrm{~kg} \mathrm{~m}^{-2} \mathrm{~s}^{-1}$ (purple shading in Fig. 7a) in the control simulation which is much larger than that in the sensitivity test, especially over the steep slopes of elevated terrain to the west. This indicates that the neighboring Taihang and Yanshan Mountains reinforce the moisture transport and the MFC of enhancing extreme precipitation over NC.

Figure 8 separates the wind convergence and advection terms of the vertically integrated MFC for the six extreme precipitation days in the control and sensitivity tests. In the control simulation, the increased MFC $\left(2.0 \times 10^{-5} \mathrm{~kg} \mathrm{~m}^{-2} \mathrm{~s}^{-1}\right)$ over $\mathrm{NC}$ is attributable to the gain of wind convergence $\left(1.73 \times 10^{-5} \mathrm{~kg} \mathrm{~m}^{-2} \mathrm{~s}^{-1}\right)$ and the increased advection $\left(2.7 \times 10^{-6} \mathrm{~kg} \mathrm{~m}^{-2} \mathrm{~s}^{-1}\right)$. For the whole $\mathrm{NC}$, the wind convergence and advection term account for $86.5 \%$ and $13.5 \%$ of the increased MFC, respectively (Table 4). In the sensitivity test, the enhanced MFC over $\mathrm{NC}$ is $1.68 \times 10^{-5} \mathrm{~kg} \mathrm{~m}^{-2} \mathrm{~s}^{-1}$, less than that in the control simulation. After removing the terrain, the convergence and advection term correspond to gains of $1.42 \times 10^{-5}$ and $2.6 \times 10^{-6} \mathrm{~kg} \mathrm{~m}^{-2} \mathrm{~s}^{-1}$ (84.5\% and $15.5 \%$ of the total MFC), respectively.

The comparison between the control and sensitivity tests demonstrates that the surrounding elevated terrain significantly enhances wind convergence, leading to the MFC 16\% higher than the case without terrain. Moreover, the most significant difference for wind convergence term between the control and sensitivity test lies in the western complex terrain region of NC. This means that the surrounding terrain plays a considerable role for creating extreme precipitation over NC.

\subsection{The circulation effects in the control and sensitivity tests}

Moisture supply, air instability and vertical motion of the air which depends on diabatic heating all play a role for 


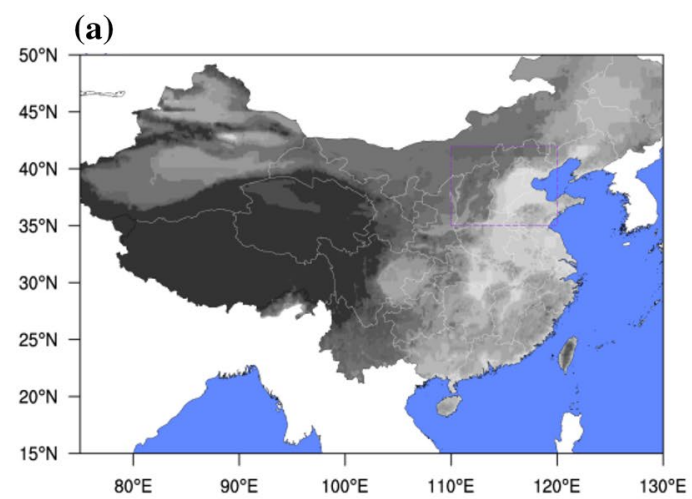

(b)
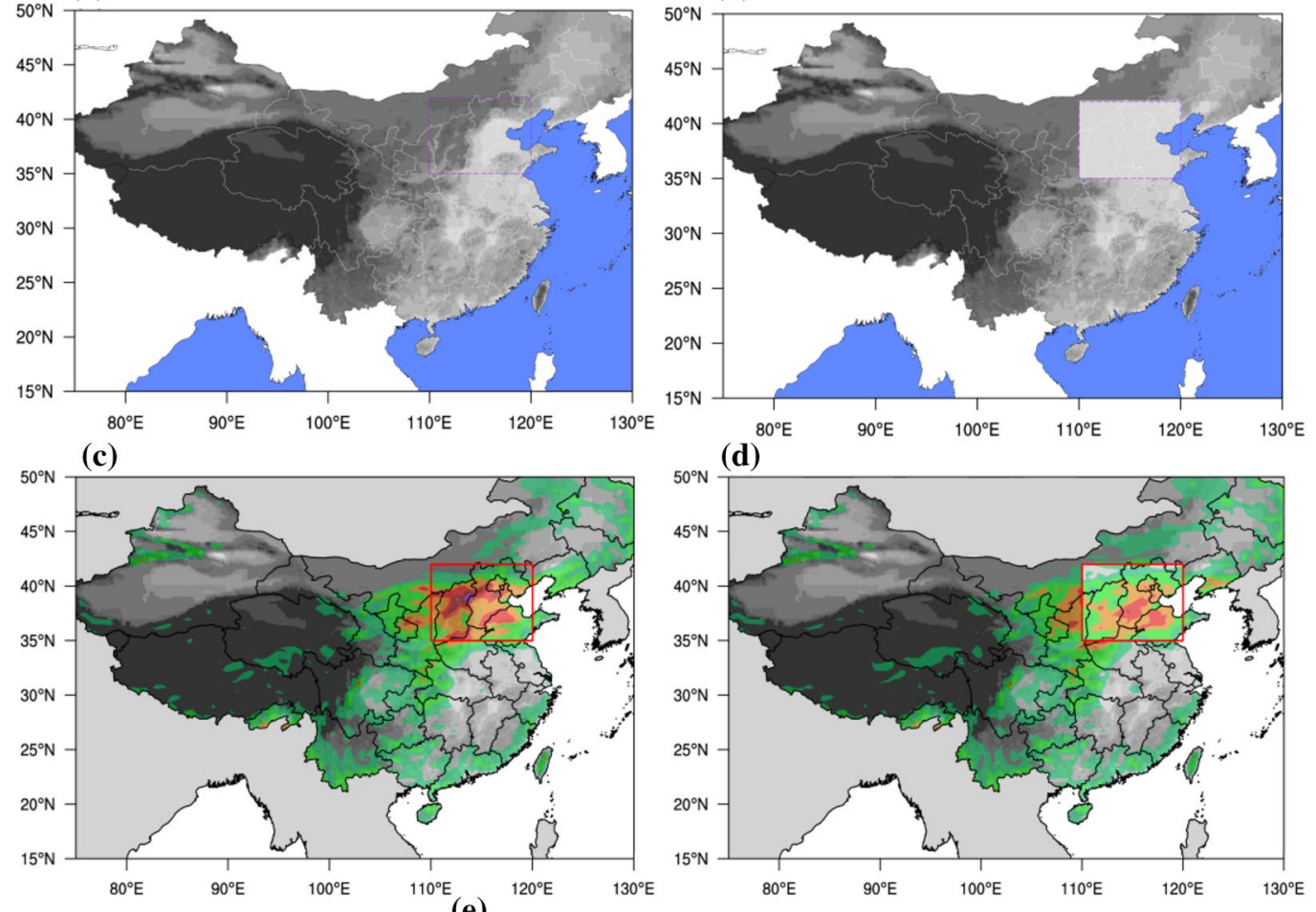

(d)
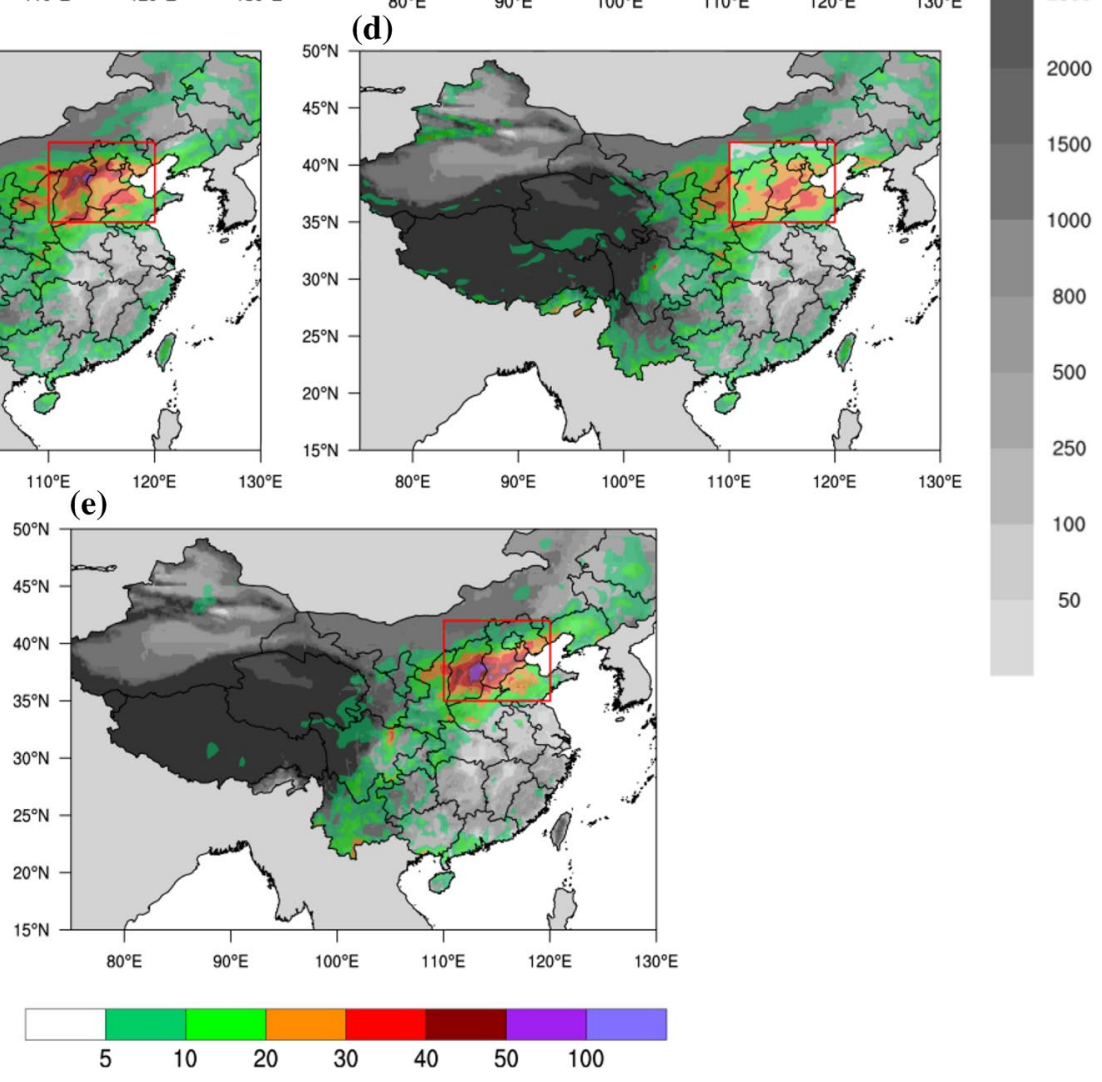

Fig. 6 Terrain height (grey shading; m) over mainland China in the a control and $\mathbf{b}$ sensitivity tests. The purple dashed rectangle denotes the NC region. c, d Composite daily mean precipitation amount (color shading, $\mathrm{mm}$ ) over mainland China for the six extreme precipitation days in the control and sensitivity tests, respectively. e

cloud formation and precipitation. Here we calculated and compared the atmospheric apparent heat $\mathrm{Q}_{1}$ and wind fields in the control and sensitivity tests, to explore the terrain effect for the extreme precipitation in NC.

As shown in Fig. 9, the whole column $\mathrm{Q}_{1}$ in the control test is obviously larger than in the sensitivity test. Especially, relatively large values of whole column $\mathrm{Q}_{1}$ is found over the complex terrain region of $\mathrm{NC}$ in the control test, while the sensitivity test shows overall small values
Observed daily mean precipitation (color shading, mm) over mainland China on the six extreme precipitation days. The red rectangle in $(\mathbf{c}-\mathbf{e})$ indicates the $\mathrm{NC}$ region and the grey shading represent terrain height (unit: $\mathrm{m}$ )

(Fig. 9a, b). This is mainly due to the increased precipitation and associated latent heat release.

The diabatic heating is helpful to make the warm moisture to rise. Moreover, at the $300 \mathrm{hPa}$ level there is a divergence structure in the western part of NC as shown in Fig. 9c. Over this region, it is thus more favourable for the upper winds to diverge, which help pump the moisture from lower level to upper level in the control test. To further explore the terrain effect for the vertical motion, we calculated the meridional 

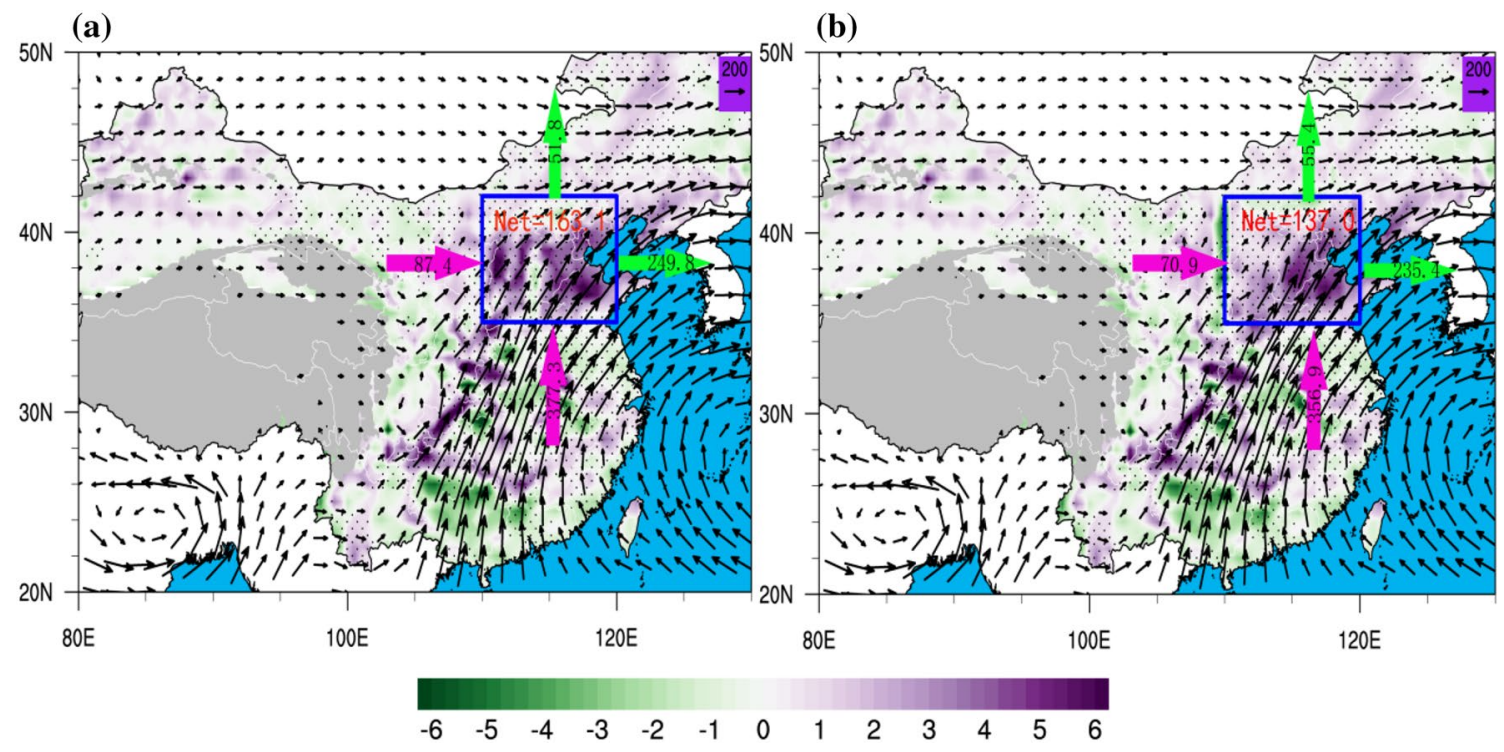

Fig. 7 Composite column-integrated moisture flux (vectors; $\mathrm{kg} \mathrm{m}^{-1}$ $\mathrm{s}^{-1}$ ) for the six extreme precipitation days in the control test (a) and sensitivity test (b). The purple shading denotes MFC and the green shading represents moisture flux divergence $\left(10^{-5} \mathrm{~kg} \mathrm{~m}^{-2} \mathrm{~s}^{-1}\right)$. The thick colored arrows and associated values represent the direction and intensity of moisture flux at each boundary $\left(\mathrm{kg} \mathrm{m}^{-1} \mathrm{~s}^{-1}\right)$. The

and zonal cross sections of $\mathrm{Q}_{1}$ along with wind vectors, and the results are shown in Fig. 10. The heating effect caused by the terrain is obviously stronger than in the sensitivity without the terrain. In the meridional cross section, the largest $\mathrm{Q}_{1}$ is located around 400-200 hPa (Fig. 10a). Compared with the sensitivity test (Fig. 10b), the vertical motion in the control test is much stronger than in the sensitivity test (Fig. 10b). Moreover, the strongest vertical motion is located over the steepest slope of the terrain region in the west. As for the zonal section (Fig. 10c, d), it shows similar results as those in the meridional section. Especially, the vertical motion in the control test is stronger than in the sensitivity test.

The warm moisture is lifted more strongly when encountering the terrain over NC. This means a higher latent heat and more heating, resulting stronger instability of the air. At the same time, the stronger vertical motion results in that the air in the upper level will be stocked, promoting the divergence structure at the upper level. With help of the thermodynamic and dynamic effects, the pumping of the moisture from the lower levels outside $\mathrm{NC}$ will be strengthened, feeding the needed moisture supply for the extreme precipitation.

\section{Conclusions and discussions}

Based on the ERA-Interim reanalysis data and rain gauge observations, this work has quantified moisture budget for the 38 selected summer extreme precipitation days over NC blue dashed rectangle indicates the NC region and the grey shading denotes part of the TP. "Net" denotes the net moisture supply to NC. The black dots indicate the statistically significant results above the $90 \%$ confidence level for magnitude of column-integrated moisture flux

during 1979-2016 and that of climatology. To improve our understanding of the role played by the orographic effect for the extreme precipitations, numerical modeling was carried for six out of the 38 extreme precipitation days. The results are summarized as follows.

1. During the 38 extreme precipitation days, there is a dominant moisture influx of $311.8 \mathrm{~kg} \mathrm{~m}^{-1} \mathrm{~s}^{-1}$ into NC along the southern boundary from the tropical oceans and a secondary influx of $107.9 \mathrm{~kg} \mathrm{~m}^{-1} \mathrm{~s}^{-1}$ across the western boundary carried by mid-latitude westerlies. In contrast, moisture flows out across the eastern boundary at $206.9 \mathrm{~kg} \mathrm{~m}^{-1} \mathrm{~s}^{-1}$ and across the northern boundary at $76.0 \mathrm{~kg} \mathrm{~m}^{-1} \mathrm{~s}^{-1}$. The corresponding net moisture budget over NC is a gain of $136.8 \mathrm{~kg} \mathrm{~m}^{-1} \mathrm{~s}^{-1}$.

2. Compared to the climatological summer mean, NC during the extreme precipitation days represents a strong moisture sink linked with intensive moisture transport, with the MFC maximum exceeding approximately $4 \times 10^{-5} \mathrm{~kg} \mathrm{~m}^{-2} \mathrm{~s}^{-1}$. The enhanced MFC that facilitates the extreme precipitations over $\mathrm{NC}$ is mainly driven by the convergence of horizontal winds rather than moisture advection.

3. The MFC maximum core, the pronounced moisture transport, and the intense extreme precipitation zone over NC are anchored to the east of the steep slopes of the surrounding elevated terrain. Moreover, the remarkable humidity "tongue" and active upward motion that 

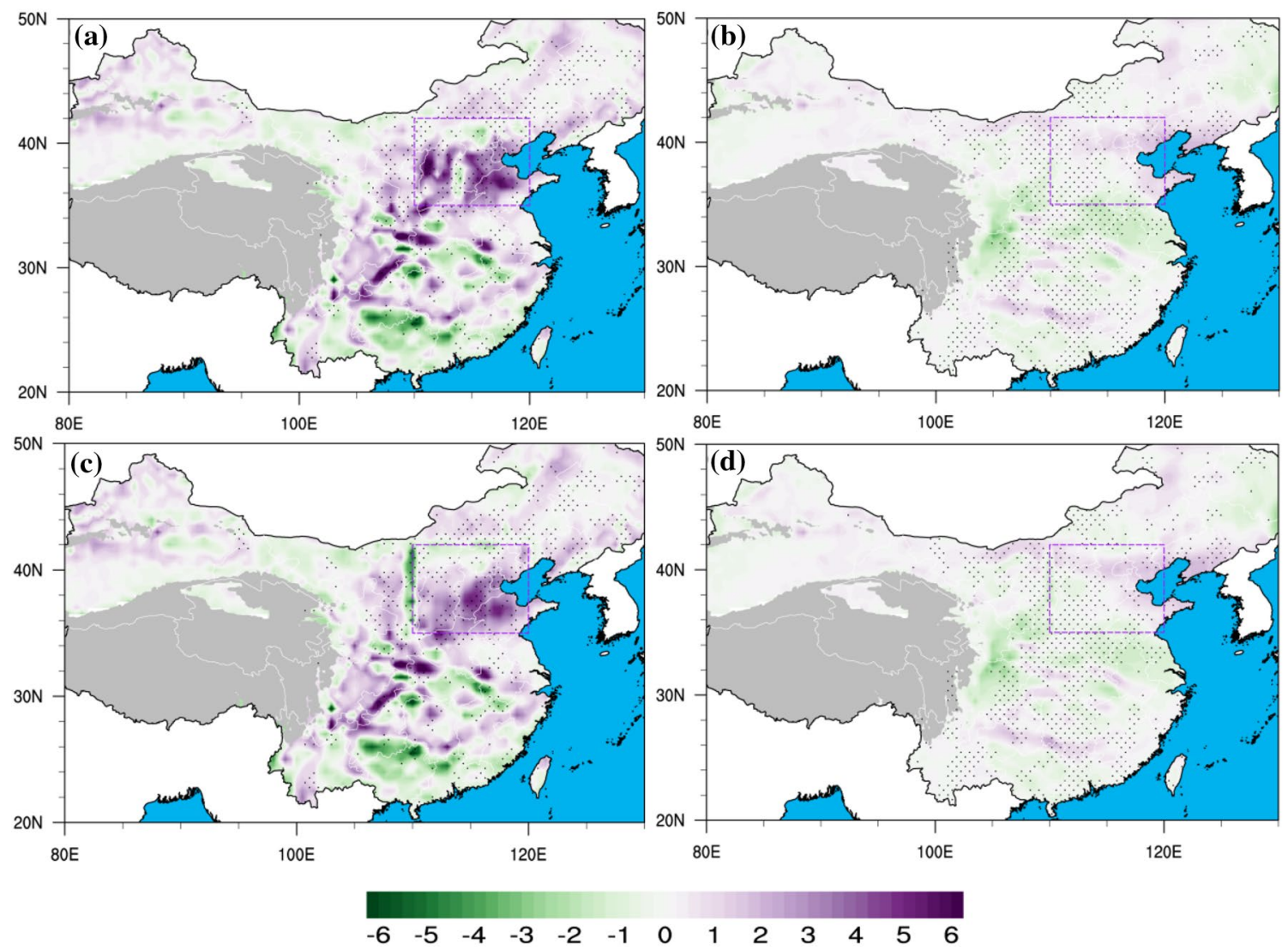

Fig. 8 a Composite wind convergence term and $\mathbf{b}$ moisture advection term (color shading; $10^{-5} \mathrm{~kg} \mathrm{~m}^{-2} \mathrm{~s}^{-1}$ ) of MFC for the six extreme precipitation days in the control simulation. $\mathbf{c}, \mathbf{d}$ As for $\mathbf{a}$ and $\mathbf{b}$, but for the sensitivity test. The grey shading indicates part of the TP. The

black dots indicate the statistically significant differences above the $90 \%$ confidence level for the wind convergence term and moisture advection term

Table 4 Contributions of wind convergence and advection to the MFC (unit: $10^{-5} \mathrm{~kg} \mathrm{~m}^{-2} \mathrm{~s}^{-1}$ ) for the whole NC in the control and sensitivity tests

\begin{tabular}{llll}
\hline & MFC $-\nabla \cdot(\mathrm{q} \vec{V})$ & Convergence $-\mathrm{q} \nabla \cdot \vec{V}$ & Advection $-\vec{V} \cdot \nabla q$ \\
\hline Control test & 2.00 & $1.73(86.5 \%)$ & $0.27(13.5 \%)$ \\
Sensitivity test & 1.68 & $1.42(84.5 \%)$ & $0.26(15.5 \%)$ \\
\hline
\end{tabular}

are conducive to extreme precipitation also occur near the steep slope of terrain over $\mathrm{NC}$, indicating the important influence of the adjacent elevated terrain on extreme precipitation over NC.

4. The WRF simulations for the six selected extreme precipitation days confirm the diagnosed results. Additionally, using the WRF simulations, the elevated terrain in the western NC is found to intensify MFC by $16 \%$ relative to the case without the terrain.

5. The terrain is found to be able to enhance upward vertical motion driven by precipitation and associated diabatic heating of the atmosphere. The vertically integrated diabatic heating and divergence at the upper level under the influence of the topography are favourable to the occurrence of extreme precipitation. Without terrain, upward motion of warm moisture air at low level would be weakened. Therefore, the western terrain of NC is considered important for the intensive extreme precipitations over the western of NC.

Apart from topography and wind convergence considered in this study, there are still other factors affecting for rainstorms over NC. The impact of ENSO on precipitation changes has been well documented (Zhang et al. 1999; Wang et al. 2016). Extreme precipitation days over NC are significantly less frequent in El Nino phases than in La Nina 


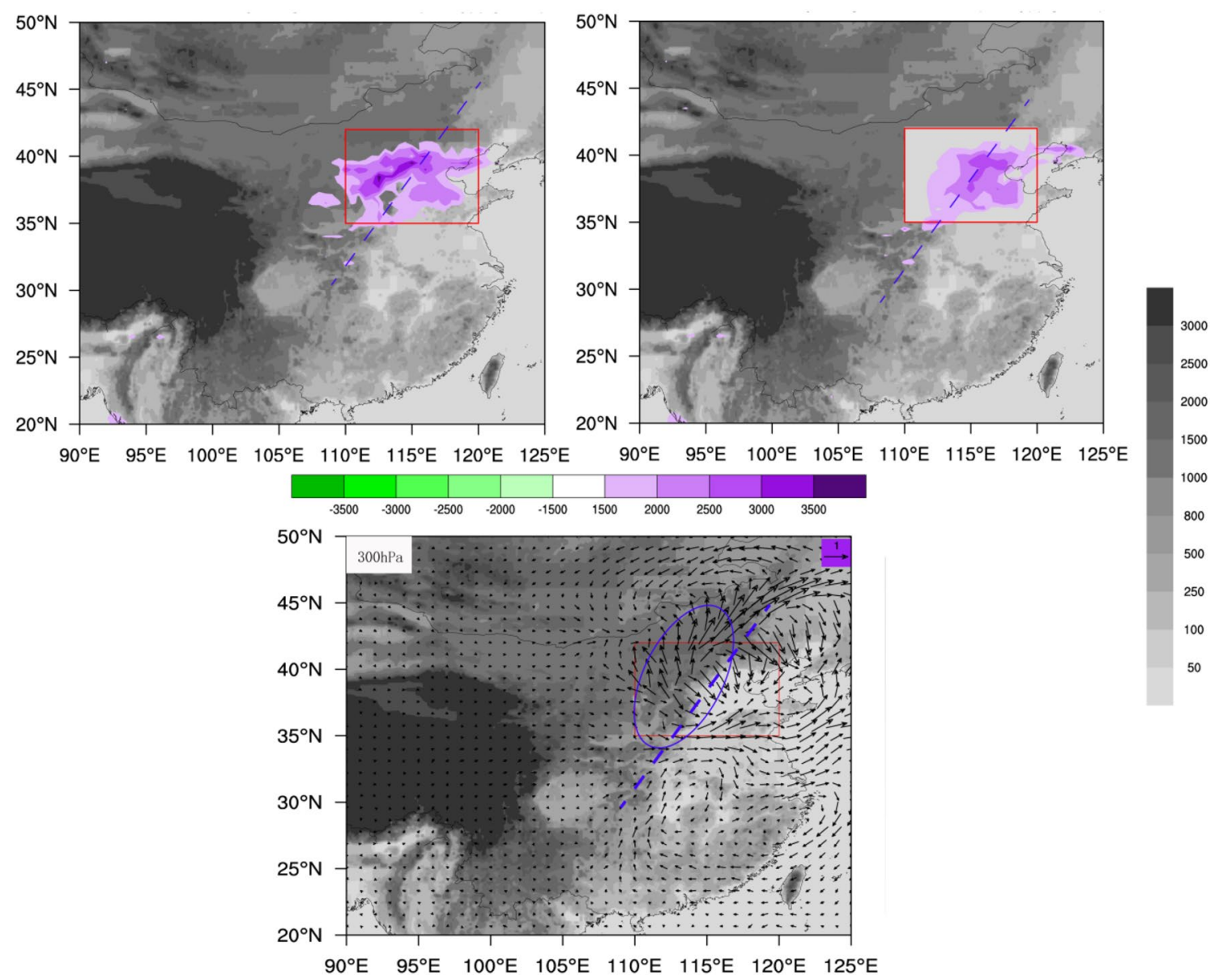

Fig. 9 The distributions of the whole layer atmospheric apparent heat $\mathrm{Q}_{1}$ (color contour; unit: $\mathrm{w} \mathrm{m}^{-2}$ ) $\mathbf{a}$ in the control test; $\mathbf{b}$ in the sensitivity test. The wind difference at $300 \mathrm{hPa}$ between control and sensitiv-

phases (Li et al. 2011). Large-scale circulation is found to maintain and favour the development of rainstorms over $\mathrm{NC}$ (Orsolini et al. 2015). When the Indian monsoon is stronger than normal state, a westward location of South Asian High corresponds to more rainfall over NC (Wei et al. 2014). Likewise, Zhang et al. (2017) found that the strength and location of western North Pacific subtropical high (WNPSH) are closely related to the changes of summer extreme precipitation in eastern China. Additionally, Wen et al. (2015) documented that the WNPSH interacting with typhoons of different intensities may contribute to the development of a southeasterly moisture channel, resulting in a change in rainstorm over NC. Further, a recent study on extreme precipitation events in eastern China also indicated a possibly ity test is shown in c. The grey shade is the terrain height (unit: $\mathrm{m}$ ). The red box represents the NC region. The blue dash line shows the terrain staircase transitional region as shown in Fig. 1c

important role of air pollution and urbanization (Shi et al. 2017).

Since the diagnostic analyses of this study were based on dynamics and thermodynamic processes relevant for precipitation, the impacts of the influencing factors discussed above are to a large extent imbedded into the processes analyzed. However, it should be kept in mind that only six out of the 38 extreme precipitation days were subject to numerical simulation due to limited computing resources. Although the results are in line with the diagnostic analyzed for the 38 days in principle, there can be some details that deserve more in-depth analyses. Future studies building on the findings of this study are thus desirable to systematically understand the dynamics of and causes behind the extreme events. 

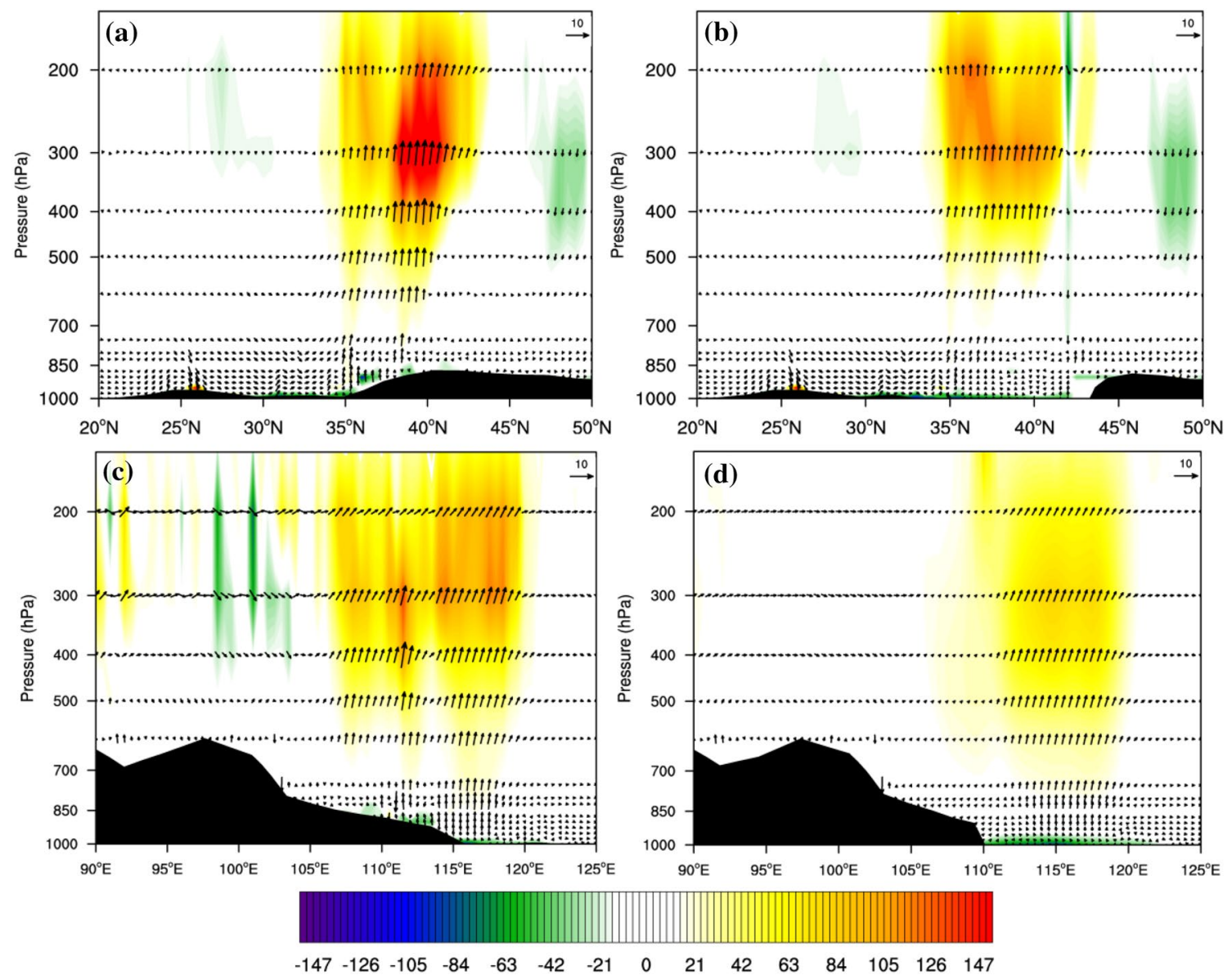

Fig. 10 The composite latitudinal and meridional cross sections of atmospheric apparent heat source $\mathrm{Q}_{1}$ (contour; unit: $10^{-4} \mathrm{~m}^{2} \mathrm{~s}^{-3}$ ) and wind fields for the six extreme precipitation days in the control test

Acknowledgements Open access funding provided by University of Gothenburg. We sincerely thank anonymous reviewers whose comments greatly improved the manuscript. We acknowledge the National Meteorological Information Center of the China Meteorological Administration for providing the observational daily precipitation dataset (http://nmic.cn/web/index.htm/), and the European Centre for Medium-Range Weather Forecasts to support reanalysis data (http:// apps.ecmwf.int/datasets/). This work was supported by the Strategic Priority Research Program of Chinese Academy of Sciences, State Key Laboratory of Drug Research (CN) (XDA20060401), Swedish STINT (CH2015-6226), The Second Tibetan Plateau Scientific Expedition and Research (STEP) program (2019QZKK0105) and Jiangsu Postgraduate Research and Innovation Program (KYCX17_0869).

Open Access This article is licensed under a Creative Commons Attribution 4.0 International License, which permits use, sharing, adaptation, distribution and reproduction in any medium or format, as long as you give appropriate credit to the original author(s) and the source, provide a link to the Creative Commons licence, and indicate if changes were made. The images or other third party material in this article are included in the article's Creative Commons licence, unless indicated otherwise in a credit line to the material. If material is not included in the article's Creative Commons licence and your intended use is not permitted by statutory regulation or exceeds the permitted use, you will $(\mathbf{a}, \mathbf{c})$ and sensitivity test $(\mathbf{b}, \mathbf{d})$. The black color represents the terrain. The meridional cross section along the $113^{\circ} \mathrm{E}$ and the zonal cross section along the $37^{\circ} \mathrm{N}$

need to obtain permission directly from the copyright holder. To view a copy of this licence, visit http://creativecommons.org/licenses/by/4.0/.

\section{References}

Banacos PC, Schultz DM (2005) The use of moisture flux convergence in forecasting convective initiation: historical and operational perspectives. Weather Forecast 20(3):351-366. https://doi. org/10.1175/WAF858.1

Chen R, Tomassiniand L (2015) The role of moisture in summertime low-level jet formation and associated rainfall over the East Asian Monsoon Region. J Atmos Sci 72(10):3871-3890. https://doi. org/10.1175/JAS-D-15-0064.1

Chen B, Xu XD, Zhao TL (2018) Quantifying oceanic moisture exports to mainland China in association with summer precipitation. Clim Dyn 51:4271. https://doi.org/10.1007/s00382-017-3925-1

Chou C, Lan CW (2012) Changes in the annual range of precipitation under global warming. J Clim 25(1):222-235. https://doi. org/10.1175/jcli-d-11-00097.1

Chou C, Neelin JD, Chen CA, Tu JY (2009) Evaluating the "rich-getricher" mechanism in tropical precipitation change under global 
warming. J Clim 22(8):1982-2005. https://doi.org/10.1175/2008J CLI2471.1

Cook KH, Vizy EK, Launer ZS, Patricola CM (2008) Springtime intensification of the Great Plains low-level jet and Midwest precipitation in GCM simulations of the twenty-first century. J Clim 21(23):6321-6340. https://doi.org/10.1175/2008jcli2355.1

Dee DP, Uppala SM, Simmons AJ, Berrisforda P, Polia P, Kobayashib S, Andrae U, Balmaseda MA, Balsamo G, Bauer P, Bechtold P, Beljaars ACM, Berg LVD, Bidlot J, Bormann N, Del C, Dragani R, Fuentes M, Geer AJ, Haimberger L, Healy SB, Hersbach H, Volm EV, Isaksen L, Kallberg P, Mohler M, Matricardi M, McNally AP, Monge-Sanz BM, Morcrette JJ, Park BK, Peubey C, Rosnay PD, Tavolato C, Thepaut JN, Vitart F (2011) The ERAinterim reanalysis: configuration and performance of the data assimilation system. Q J R Meteorol Soc 137(656):553-597. https ://doi.org/10.1002/qj.828

Ding YH, Wang ZY, Sun Y (2010) Inter-decadal variation of the summer precipitation in East China and its association with decreasing Asian summer monsoon. Part I: Observed evidences. Int J Climatol 28(9):1139-1161. https://doi.org/10.1002/joc.1615

Fankhauser JC (1965) A comparison of kinematically computed precipitation with observed convective rainfall, vol 25. National Severe Storms Laboratory Rep

Freychet N, Hsu HH, Chou C, Wu CH (2015) Asian summer monsoon in CMIP5 projections: a link between the change in extreme precipitation and monsoon dynamics. J Clim 28(4):1477-1493. https ://doi.org/10.1175/JCLI-D-14-00449.1

Gao T, Wang H (2017) Trends in precipitation extremes over the Yellow River basin in North China: changing properties and causes. Hydrol Process 31:2412-2428. https://doi.org/10.1002/hyp.11192

Gemmer M, Jiang T, Su BD, Zbigniew WK (2008) Seasonal precipitation changes in the wet season and their influence on flood/ drought hazards in the Yangtze River Basin, China. Quat Int 186(1):12-21. https://doi.org/10.1016/j.quaint.2007.10.001

Guo Y, Li J, Li Y (2012) A time-scale decomposition approach to statistically downscale summer rainfall over North China. J Clim 25(2):572-591. https://doi.org/10.1175/JCLI-D-11-00014 .1

He HZ, Zhang FQ (2010) Diurnal variations of warm-season precipitation over northern China. Mon Weather Rev 138(4):1017-1025. https://doi.org/10.1175/2010mwr3356.1

Holman KD, Vavrus SJ (2012) Understanding simulated extreme precipitation events in Madison, Wisconsin, and the role of moisture flux convergence during the late twentieth and twenty-first centuries. J Hydrometeorol 13(3):877-894. https://doi.org/10.1175/ jhm-d-11-052.1

Hu Y, Deng Y, Zhou ZM, Cui CG, Dong XQ (2018) A statistical and dynamical characterization of large-scale circulation patterns associated with summer extreme precipitation over the middle reaches of Yangtze river. Clim Dyn. https://doi.org/10.1007/s0038 2-018-4501-Z

Jiang XM, Yuan HL, Xue M, Chen X, Tan XG (2014) Analysis of a heavy rainfall event over Beijing during 21-22 July 2012 based on high resolution model analyses and forecasts. J Meteorol Res 28(2):199-212. https://doi.org/10.1007/s13351-014-3139-y

Jonkman SN (2005) Global perspectives on loss of human life caused by floods. Nat Hazards 34(2):151-175. https://doi.org/10.1007/ s11069-004-8891-3

Kain JS, Fritsch JM (1993) Convective parameterization for mesoscale models: the Kain-Fritsch Scheme. Meteorol Monogr 24:165-170. https://doi.org/10.1007/978-1-935704-13-3_16

Li W, Zhai PM, Cai J (2011) Research on the relationship of ENSO and the frequency of extreme precipitation events in China. Adv Clim Change Res 02:47-53. https://doi.org/10.3724/ SP.J.1248.2011.00101
Li HQ, Cui XP, Zhang DL (2017) A statistical analysis of hourly heavy rainfall events over the Beijing metropolitan region during the warm seasons of 2007-2014. Int J Climatol 37(11):4027-4042. https://doi.org/10.1002/joc.4983

Liang P, He JH, Chen LX, Li W (2007) Anomalous moisture sources for the severe precipitation over North China during summer. Plateau Meteorol 26(3):460-465. https://doi.org/10.1002/jrs.1570 (in Chinese)

Liao F, Hu YM, Hong YC (2009) Numerical study for the influences of orographic dynamic on cloud and precipitation in North China. Plateau Meteorol 28(1):115-126. https://doi.org/10.1016/S1003 -6326(09)60084-4 (in Chinese)

Liu J, Wang SY (2013) Analysis of human vulnerability to the extreme rainfall event on 21-22 July 2012 in Beijing, China. Nat Hazard Earth Syst 13(11):2911-2926. https://doi.org/10.5194/nhess -13-2911-2013

Liu X, Bai A, Liu C (2009) Diurnal variations of summertime precipitation over the Tibetan Plateau in relation to orographicallyinduced regional circulations. Environ Res Lett 4(4):045203. https ://doi.org/10.1088/1748-9326/4/4/045203

Luo YL, Wu MW, Ren FM, Li J, Wong WK (2016) Synoptic situations of extreme hourly precipitation over China. J Clim 29(24):87038719. https://doi.org/10.1175/JCLI-D-16-0057.1

Ma YZ, Lu CG, Gao ST (2012) The effects of different microphysical schemes in WRF on a heavy rainfall in North China during 18-19 August 2010. Chin J Atmos Sci 36(4):835-850. https://doi. org/10.1007/s11783-011-0280-z (in Chinese)

Mirza MMQ (2002) Global warming and changes in the probability of occurrence of floods in Bangladesh and implications. Glob Environ Change 12(2):1-138. https://doi.org/10.1016/s0959 $-3780(02) 00002-\mathrm{x}$

Orsolini YJ, Zhang L, Peters DHW, Fraedrich K, Zhu XH, Schneidereit A, Hurk BVD (2015) Extreme precipitation events over north China in August 2010 and their link to eastward-propagating wave-trains across Eurasia: observations and monthly forecasting. Q J R Meteorol Soc 141(693):3097-3105. https://doi.org/10.1002/ qj.2594

Şahin S, Murat T, Wang SH, Hannah D, Eastwood W (2015) Large scale moisture flux characteristics of the Mediterranean basin and their relationships with drier and wetter climate conditions. Clim Dyn 45(11):1-21. https://doi.org/10.1007/s00382-015-2545-x

Seo KH, Ok J, Son JH, Cha DH (2013) Assessing future changes in the East Asian summer monsoon using CMIP5 coupled models. J Clim 26(19):7662-7675. https://doi.org/10.1175/JCLID-12-00694.1

Shi P, Bai X, Kong F, Fang J, Gong D, Zhou T, Guo Y, Liu Y, Dong W, Wei Z, He C, Yu D, Wang J, Ye Q, Yu R, Chen D (2017) Urbanization and air quality as major drivers of altered spatiotemporal patterns of heavy rainfall in China. Landsc Ecol 32(8):1723-1738. https://doi.org/10.1007/s10980-017-0538-3

Skamarock WC, Klemp JB (2008) A time-split nonhydrostatic atmospheric model for weather research and forecasting applications. J Comput Phys 227(7):3465-3485. https://doi.org/10.1016/j. jcp.2007.01.037

Sun W, Li J, Yu RC, Yuan WH (2015) Two major circulation structures leading to heavy summer rainfall over central North China. J Geophys Res Atmos 120(10):4466-4482. https://doi. org/10.1002/2014JD022853

Tian B, Fan K (2013) Factors favorable to frequent extreme precipitation in the upper Yangtze River Valley. Meteorol Atmos Phys 121(3-4):189-197. https://doi.org/10.1007/s00703-013-0261-9

Tian J, Liu J, Wang J, Li CZ, Chu ZG (2017) A spatio-temporal evaluation of the WRF physical parameterisations for numerical rainfall simulation in semi-humid and semi-arid catchments of Northern China. Atmos Res 191:141-155. https://doi.org/10.1016/j.atmos res.2017.03.012 
Wang XM, Liu Y (2017) Causes of extreme rainfall in May 2013 over Henan Province: the role of the southwest vortex and low-level jet. Theor Appl Climatol 129(1-2):701-709. https://doi.org/10.1007/ s00704-017-2054-4

Wang WG, Shao QX, Yang T, Peng SG, Yu ZB, Taylor J, Xing WQ, Zhao CP, Sun FC (2013) Changes in daily temperature and precipitation extremes in the Yellow River Basin, China. Stoch Environ Res Risk Assess 27(2):401-421. https://doi.org/10.1007/s0047 7-012-0615-8

Wang CX, Gao ST, Liang L, Deng DF, Gong HN (2014) Multi-scale characteristics of moisture transport during a rainstorm process in North China. Atmos Res 145-146:189-204. https://doi. org/10.1016/j.atmosres.2014.04.008

Wang Y, Zhang Q, Singh VP (2016) Spatiotemporal patterns of precipitation regimes in the Huai River basin, China, and possible relations with ENSO events. Nat Hazards 82(3):2167-2185. https ://doi.org/10.1007/s11069-016-2303-3

Wei W, Zhang RH, Wen M, Rong XY, Li T (2014) Impacts of Indian summer monsoon on the South Asian High and its influence on summer rainfall over China. Clim Dyn 43:1257-1269. https://doi. org/10.1007/s00382-013-1938-y

Wen YR, Xue L, Li Y, Wei N, Lv AM (2015) Interaction between Typhoon Vicente (1208) and the western Pacific subtropical high during the Beijing extreme rainfall of 21 July 2012. J Meteorol Res 29(2):293-304. https://doi.org/10.1007/s13351-015-4097-8

Yoon JH, Chen TC (2005) Water vapor budget of the Indian monsoon depression. Tellus A 57(5):770-782. https://doi.org/10.3402/tellu sa.v57i5.14737

Yu ET (2013) Climatic response to changes in vegetation in the Northwest Hetao Plain as simulated by the WRF model. Int J Climatol 33(6):1470-1481. https://doi.org/10.1002/joc.3527

Zhai PM, Zhang XB, Wan H, Pan XH (2005) Trends in total precipitation and frequency of daily precipitation extremes over China. J Clim 18(7):1096-1108. https://doi.org/10.1175/JCLI-3318.1

Zhang RH (1999) The role of Indian summer monsoon water vapor transportation on the summer rainfall anomalies in the northern part of China during the El Nino mature phase. Plateau Meteorol 18(4):567-574 (in Chinese)

Zhang C, Li Q (2014) Tracking the moisture sources of an extreme precipitation event in Shandong, China in July 2007: a computational analysis. J Meteorol Res 28(4):634-644. https://doi.org/10.1007/ s13351-014-3084-9

Zhang RH, Zhao P, Zhang Q, Zhang ZF, Cao LJ, Yang YR, Zou FL, Zhao YF, Zhao HM, Chen Z (1999) Quality control procedures for hourly precipitation data from automatic weather stations in China. Meteorol Mon 36(7):123-132. https://doi.org/10.3788/ HPLPB20102207.1462 (in Chinese)

Zhang ZX, Tao H, Zhang Q, Zhang JC, Forher N, Hormann G (2010) Moisture budget variations in the Yangtze River Basin, China, and possible associations with large-scale circulation. Stoch Environ Res Risk Assess 24(5):579-589. https://doi.org/10.1007/s0047 7-009-0338-7

Zhang DL, Lin Y, Zhao P, Yu XD, Wang SQ, Kang HW, Ding YH (2013) The Beijing extreme rainfall of 21 July 2012:"Right results" but for wrong reasons. Geophys Res Lett 40(7):14261431. https://doi.org/10.1002/grl.50304

Zhang Q, Zhao YF, Fan SH (2016) Development of hourly precipitation datasets for national meteorological stations in China. Torrential Rain Disasters 35(2):182-186. https://doi.org/10.3969/j. issn.1004-9045.2016.02.011 (in Chinese)

Zhang Q, Zheng YJ, Singh VP, Luo M, Xie ZH (2017) Summer extreme precipitation in eastern China: mechanisms and impacts. J Geophys Res Atmos 122(5):2278-2766. https://doi. org/10.1002/2016JD025913
Zhao Y, Cui XP, Gao ST (2010) Richardson number in a moist atmosphere and its application in the analysis of heavy rainfall events. Acta Meteorol Sin 24(1):95-103. https://doi.org/10.1029/2009R S004194

Zhao YY, Zhang QH, Du Y, Jiang M, Zhang JP (2013) Objective analysis of circulation extremes during the 21 July 2012 torrential rain in Beijing. Acta Meteorol Sin 27(5):626-635. https://doi. org/10.1007/s13351-013-0507-y

Zhao Y, Xu XD, Chen B, Wang YJ (2016) The upstream "strong signals" of the water vapor transport over the Tibetan Plateau during a heavy rainfall event in the Yangtze River Basin. Adv Atmos Sci 33(12):1343-1350. https://doi.org/10.1007/s00376-016-6118-7

Zhao Y, Xu XD, Liu LP, Zhang R, Xu HX, Wang YJ, Li J (2018a) Effects of convection over the Tibetan Plateau on rainstorms downstream of the Yangtze River Basin. Atmos Res 219:24-35. https://doi.org/10.1016/j.atmosres.2018.12.019

Zhao Y, Xu XD, Ruan Z, Chen B, Wang F (2018b) Precursory strongsignal characteristics of the convective clouds of the Central Tibetan Plateau detected by radar echoes with respect to the evolutionary processes of an eastward-moving heavy rainstorm belt in the Yangtze River Basin. Meteorol Atmos Phys 131(4):697-712. https://doi.org/10.1007/s00703-018-0597-2

Zhao Y, Xu XD, Zhao TL, Yang XJ (2019a) Effects of the Tibetan Plateau and its second staircase terrain on rainstorms over North China: from the perspective of water vapor transport. Int J Climatol 39(7):3121-3133. https://doi.org/10.1002/joc.6000

Zhao Y, Wang MZ, Li J, Yang XJ, Zhang N, Chen H (2019b) Diurnal variations in summer precipitation over the Yellow River Basin. Adv Meteorol. https://doi.org/10.1155/2019/2482656

Zhong S, Yang XQ (2015) Ensemble simulations of the urban effect on a summer rainfall event in the Great Beijing Metropolitan Area. Atmos Res 153:318-334. https://doi.org/10.1016/j.atmos res.2014.09.005

Zhong LZ, Mu R, Zhang DL, Zhao P, Zhang ZQ, Wang N (2015) An observational analysis of warm-sector rainfall characteristics associated with the 21 July 2012 Beijing extreme rainfall event. J Geophys Res Atmos 120(8):3274-3291. https://doi.org/10.1002/2014J D022686

Zhong L, Zhang Z, Chen L, Yang JH, Zou FL (2016) Application of the Doppler weather radar in real-time quality control of hourly gauge precipitation in eastern China. Atmos Res 172-173(173):109_ 118. https://doi.org/10.1016/j.atmosres.2015.12.016

Zhou TJ, Yu RC (2005) Atmospheric water vapor transport associated with typical anomalous summer rainfall patterns in China. $\mathrm{J}$ Geophys Res Atmos 110:D08104. https://doi.org/10.1029/2004J D005413

Zhou T, Song F, Lin R, Chen XD (2013) The 2012 North China Floods: explaining an extreme rainfall event in the context of a longerterm drying tendency. Bull Am Meteorol Soc 94(9):S49-S51

Zhou S, Huang G, Huang P (2017) Changes in the East Asian summer monsoon rainfall under global warming: moisture budget decompositions and the sources of uncertainty. Clim Dyn 51(4):13631373. https://doi.org/10.1007/s00382-017-3959-4

Zhu QG (2007) Principles and methods of meteorology. China Meteorological Press, Beijing, pp 329-330 (in Chinese)

Zomeren JV, Delden AV (2007) Vertically integrated moisture flux convergence as a predictor of thunderstorms. Atmos Res 83(24):1-445. https://doi.org/10.1016/j.atmosres.2005.08.015

Publisher's Note Springer Nature remains neutral with regard to jurisdictional claims in published maps and institutional affiliations. 